\title{
Dynamical Analysis of Long Fiber-Reinforced Laminated Plates with Elastically Restrained Edges
}

\author{
Liz G. Nallim, ${ }^{1}$ Facundo J. Bellomo, ${ }^{1}$ Ricardo D. Quinteros, ${ }^{1}$ and Sergio Oller ${ }^{2}$ \\ ${ }^{1}$ INIQUI-CONICET, Facultad de Ingeniería, Universidad Nacional de Salta, Avenue Bolivia 5150, 4400 Salta, Argentina \\ ${ }^{2}$ International Center for Numerical Method in Engineering, (CIMNE) Technical University of Catalonia-Barcelona Tech (UPC), \\ Edif. C1, Campus Nord, Jordi Girona 1-3, 08034 Barcelona, Spain
}

Correspondence should be addressed to Liz G. Nallim, lnallim@unsa.edu.ar

Received 30 December 2010; Revised 7 August 2011; Accepted 14 September 2011

Academic Editor: Kok Keong Choong

Copyright () 2012 Liz G. Nallim et al. This is an open access article distributed under the Creative Commons Attribution License, which permits unrestricted use, distribution, and reproduction in any medium, provided the original work is properly cited.

\begin{abstract}
This paper presents a variational formulation for the free vibration analysis of unsymmetrically laminated composite plates with elastically restrained edges. The study includes a micromechanics approach that allows starting the study considering each layer as constituted by long unidirectional fibers in a continuous matrix. The Mori-Tanaka method is used to predict the mechanical properties of each lamina as a function of the elastic properties of the components and of the fiber volume fraction. The resulting mechanical properties for each lamina are included in a general Ritz formulation developed to analyze the free vibration response of thick laminated anisotropic plates resting on elastic supports. Comprehensive numerical examples are computed to validate the present method, and the effects of the different mechanical and geometrical parameters on the dynamical behavior of different laminated plates are shown. New results for general unsymmetrical laminates with elastically restrained edges are also presented. The analytical approximate solution obtained in this paper can also be useful as a basis to deal with optimization problems under, for instance, frequency constraints.
\end{abstract}

\section{Introduction}

Fiber-reinforced composite laminated plates are extensively used in many engineering applications. The free vibration analysis of these plates plays a very important role in the design of civil, aerospace, mechanical, and marine structures. In addition to the favorable high specific strength and high specific stiffness, fiber-reinforced composite laminates offer the possibility of optimal design through the variation of stacking pattern, angle of fiber orientation, fiber content, and so forth, known as composite tailoring. All these mechanical and geometrical characteristics, as well as the various coupling effects that take place, must be considered in the prediction of the laminates dynamical response to assure that this is reliable, accurate, and adequate to the design requirements.

It is well known that laminated composite plates have relatively low transverse shear stiffness, playing the shear deformation an important role in the global and local behavior of these structures. Among the numerous theories used for laminated plates that include the transverse shear strain, the first-order shear deformation theory (FSDT) $[1,2]$ is adequate for the computation of global responses (such as natural frequencies) and simultaneously has some advantages due to its simplicity and low computational cost. Many investigations have been reported for free vibration analysis of moderately thick composite laminates using the FSDT kinematics (see for instance [3-13]). However, the results are, in most cases, limited to certain lamination schemes and boundary conditions. As far as the study of thick plates with elastically restrained edges is concerned, most of the previous works are limited to isotropic ones ([14-19] among others). But, limited information is found for the case of thick anisotropic laminated plates resting on elastic supports. For instance, Setoodeh and Karami [20] implemented a layerwise laminated plate theory linked with three-dimensional elasticity approach for vibration and buckling of symmetric and antisymmetric fiber-reinforced composite plates having elastically restraint edges support and results for cross-ply laminates are presented, whereas Karami et al. [21] applied the differential quadrature method for the free vibration 
analysis of moderately thick symmetric laminated plates with elastically restrained edges. For the same boundary conditions, semianalytical solutions for the free vibration of angle-ply symmetrically laminated plates were presented by Ashour [22]. Nallim and Grossi [23] also studied the vibration of symmetric laminated plates resting on elastic support employing the Ritz method and beam orthogonal polynomials as approximated functions. These kind of approximate functions (in one or two variables) have been used by many authors to the free vibration analysis of, both homogeneous and nonhomogeneous, plates (Chakraverty et al. [24-26] and Chow et al. [27], among others).

In this paper, a general Ritz formulation for the free vibration analysis of anisotropic laminated plates is developed. All kind of boundary conditions including elastically restrained edges are considered enhancing the study. This feature allows a more realistic analysis of some structural problems. The analysis includes a micromechanical approach (according to the classification of Altenbach et al. [28]), where the average mechanical properties of each anisotropic lamina are estimated from the known characteristics of the fibers and the matrix materials taking into account the fiber volume ratio and the fiber-packing arrangement. At structural level, the dynamic response of the unsymmetrical laminated plate, with elastically restrained edges, is analyzed using the first-order shear deformation theory and the Ritz method with beam orthogonal polynomials as coordinate functions. The approximate analytical solution developed here is very useful to understand, both qualitatively and quantitatively, the behavior of complex laminated plates.

\section{Formulation}

\subsection{Effective Elastic Moduli of Long Fiber-Reinforced Laminae.} The micromechanics-based Mori-Tanaka method [29] is used in this section to predict the elastic mechanical properties of the orthotropic unidirectional laminae. This method may be viewed as the simplest mean field approach for inhomogeneous materials that encompass the full physical range of phase volume fraction.

Eshelby's results [33] show that if an elastic homogeneous ellipsoidal inclusion in an infinite linear elastic matrix is subjected to an eigenstrain $\boldsymbol{\varepsilon}^{T}$, uniform strain states $\boldsymbol{\varepsilon}^{C}$ is induced, and it is related to the eigenstrain by the expression

$$
\boldsymbol{\varepsilon}^{C}=\mathbf{S}^{E}: \boldsymbol{\varepsilon}^{T},
$$

where $\mathbf{S}^{E}$ is the Eshelby tensor, which depends on the reinforcement dimensions and the Poisson ratio of the matrix $v_{m}$. The components of this tensor for a circular, cylindrical inclusion with an infinite length-to-diameter ratio parallel to the 1-axis (parallel to the fiber direction, Figure 1) are

$$
\begin{aligned}
S_{1111}=S_{1133}=S_{1122}=0, & S_{3333}=S_{2222}=\frac{5-4 v_{m}}{8\left(1-v_{m}\right)}, \\
S_{3322}=S_{2233}=\frac{4 v_{m}-1}{8\left(1-v_{m}\right)}, & S_{3311}=S_{2211}=\frac{\nu_{m}}{2\left(1-v_{m}\right)}, \\
S_{3232}=\frac{3-4 v_{m}}{8\left(1-v_{m}\right)}, & S_{1313}=S_{1212}=\frac{1}{4} .
\end{aligned}
$$

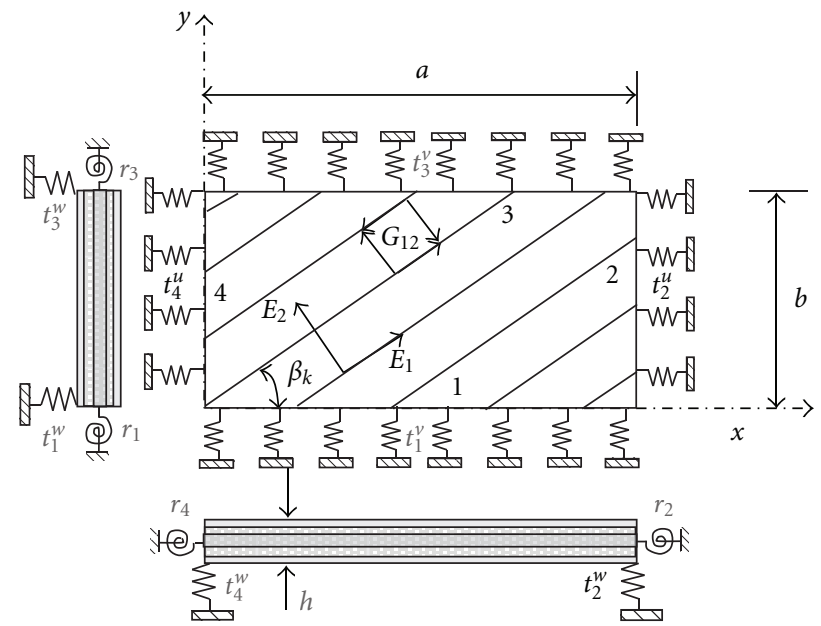

FIGURE 1: General laminated plate resting on elastic supports.

The transformations strains are obtained considering the equivalent homogeneous inclusion for inhomogeneous inclusions developed by Eshelby [33] together with the interaction effects of Mori-Tanaka [29]. These transformations strains are used to equate the total stresses in the inhomogeneities and their equivalent inclusions, as described in the following equation:

$$
\mathrm{C}_{f}:\left(\boldsymbol{\varepsilon}^{a}+\boldsymbol{\varepsilon}^{\mathrm{int}}+\boldsymbol{\varepsilon}^{C}\right)=\mathrm{C}_{m}:\left(\boldsymbol{\varepsilon}^{a}+\boldsymbol{\varepsilon}^{\mathrm{int}}+\boldsymbol{\varepsilon}^{C}-\boldsymbol{\varepsilon}^{T}\right),
$$

where $\mathbf{C}_{f}$ and $\mathbf{C}_{m}$ are the stiffness tensors of fiber and matrix, respectively, $\boldsymbol{\varepsilon}^{a}$ is the uniform far field strain applied to the domain at infinity, and $\boldsymbol{\varepsilon}^{\text {int }}$ is the average elastic strain defined by Mori-Tanaka which is given by

$$
\boldsymbol{\varepsilon}^{\mathrm{int}}=-k_{f}\left(\varepsilon^{C}-\boldsymbol{\varepsilon}^{\mathrm{T}}\right),
$$

where $k_{f}$ is the fiber volume fraction.

Finally, the stiffness tensor $\mathbf{C}$ for different unidirectional laminae can be obtained from energy considerations [34] and (1) to (4) as

$$
\begin{aligned}
\mathbf{C}=\mathbf{C}_{m} \times\{\mathbf{I} & -k_{f}\left[\left(\mathbf{C}_{f}-\mathbf{C}_{m}\right)\left(\mathbf{S}^{E}-k_{f}\left(\mathbf{S}^{E}-\mathbf{I}\right)+\mathbf{C}_{m}\right)\right]^{-1} \\
& \left.\times\left(\mathbf{C}_{f}-\mathbf{C}_{m}\right)\right\}^{-1},
\end{aligned}
$$

where $\mathbf{I}$ is the fourth order identity tensor.

Using this method the mechanical properties of unidirectional carbon/epoxy laminae are found considering various fiber volume fractions, and they are depicted in Table 1. These properties, for each unidirectional lamina, are then used in the next section to obtain the reduced constitutive matrix.

2.2. General Laminated Plate Resting on Elastic Supports. Let us consider a rectangular fiber-reinforced composite laminated plate, of dimension $a \times b$ and total thickness $h$ 
TABLE 1: Mechanical properties of unidirectional laminae (AS43501-6), obtained using Mori-Tanaka method. Fiber and matrix properties $E_{f 1}=225 \mathrm{GPa}, E_{f 2}=15 \mathrm{GPa}, G_{f 12}=15 \mathrm{GPa}, G_{f 23}=$ $7 \mathrm{GPa}, v_{f 12}=0.20 ; E_{m}=4.2 \mathrm{GPa}, v_{m}=0.34([30])$.

\begin{tabular}{lcccccccc}
\hline$k_{f}$ & 0.1 & 0.2 & 0.3 & 0.4 & 0.5 & 0.6 & 0.7 & 0.8 \\
\hline$E_{1}$ & 26.29 & 48.38 & 70.46 & 92.54 & 114.62 & 136.70 & 158.78 & 180.86 \\
$E_{2}$ & 5.11 & 5.69 & 6.31 & 7.01 & 7.81 & 8.76 & 9.87 & 11.23 \\
$G_{12}=G_{13}$ & 1.84 & 2.17 & 2.57 & 3.07 & 3.70 & 4.54 & 5.68 & 7.35 \\
$G_{23}$ & 1.75 & 1.97 & 2.22 & 2.52 & 2.88 & 3.32 & 3.88 & 4.61 \\
$n_{12}$ & 0.32 & 0.31 & 0.29 & 0.28 & 0.27 & 0.25 & 0.24 & 0.23 \\
\hline
\end{tabular}

( $h=\sum h_{k}, h_{k}$ represents the thickness of a layer). The laminated plate is composed of an arbitrary number of $N_{c}$ orthotropic layers and fibre orientation $\beta_{k}\left(k=1,2, \ldots, N_{c}\right)$ as shown in Figure 1. A rectangular Cartesian coordinate system $(x, y, z)$ is used to represent the plate geometry and the strain-displacement relations. The $x-y$ plane coincides with the middle plane of the plate. The displacement field of the first-order shear deformation theory is assumed to be of the form $[1,2]$

$$
\begin{aligned}
u(x, y, z, t) & =u_{0}(x, y, t)+z \phi_{x}(x, y, t), \\
v(x, y, z, t) & =v_{0}(x, y, t)+z \phi_{y}(x, y, t), \\
w(x, y, z, t) & =w_{0}(x, y, t),
\end{aligned}
$$

where $t$ is the time dimension $u_{0}, v_{0}$ and $w_{0}$ denote the midsurface translational displacements along the $x, y$, and $z$ axes, and $\phi_{x}, \phi_{y}$ are the rotations about $y$ - and $x$-axes, respectively. The displacement model (6) yields the following kinematic relations:

$$
\{\varepsilon\}=\left[\begin{array}{c}
\left\{\varepsilon_{0}\right\} \\
\left\{\varepsilon_{0}^{*}\right\}
\end{array}\right]+z\left[\begin{array}{c}
\left\{\varepsilon_{1}\right\} \\
\{0\}
\end{array}\right],
$$

where

$$
\begin{aligned}
\{\varepsilon\}^{T} & =\left\{\varepsilon_{x}, \varepsilon_{y}, \gamma_{x y}, \gamma_{y z}, \gamma_{x z}\right\}, \\
\left\{\varepsilon_{0}\right\}^{T} & =\left\{\frac{\partial u_{0}}{\partial x}, \frac{\partial v_{0}}{\partial y}, \frac{\partial u_{0}}{\partial y}+\frac{\partial v_{0}}{\partial x}\right\}, \\
\left\{\varepsilon_{0}^{*}\right\}^{T} & =\left\{\frac{\partial w_{0}}{\partial y}+\phi_{y}, \frac{\partial w_{0}}{\partial x}+\phi_{x}\right\}, \\
\left\{\varepsilon_{1}\right\}^{T} & =\left\{\frac{\partial \phi_{x}}{\partial x}, \frac{\partial \phi_{y}}{\partial y}, \frac{\partial \phi_{x}}{\partial y}+\frac{\partial \phi_{y}}{\partial x}\right\} .
\end{aligned}
$$

The stress-strain relation of each layer is given by the generalized Hooke's law as follows:

$$
\left(\begin{array}{c}
\sigma_{x} \\
\sigma_{y} \\
\tau_{x y} \\
\tau_{y z} \\
\tau_{x z}
\end{array}\right)^{(k)}=\left[\begin{array}{ccccc}
\bar{Q}_{11} & \bar{Q}_{12} & \bar{Q}_{16} & 0 & 0 \\
\bar{Q}_{12} & \bar{Q}_{22} & \bar{Q}_{26} & 0 & 0 \\
\bar{Q}_{16} & \bar{Q}_{26} & \bar{Q}_{66} & 0 & 0 \\
0 & 0 & 0 & \bar{Q}_{44} & \bar{Q}_{45} \\
0 & 0 & 0 & \bar{Q}_{45} & \bar{Q}_{55}
\end{array}\right]^{(k)}\left[\begin{array}{c}
\varepsilon_{x} \\
\varepsilon_{y} \\
\gamma_{x y} \\
\gamma_{y z} \\
\gamma_{x z}
\end{array}\right],
$$

where $\bar{Q}_{i j}$ are the components of the plane-stress reduced constitutive matrix [35] which are function of the elastic constant determined in Section 2.1 and the ply angle $\beta_{k}$.

2.3. Energy Functional Components. Taking into account (7) and (9), the strain energy due to the laminated plate deflection can be written as

$$
\begin{gathered}
U_{p}=\frac{1}{2} \iint_{R}\left[\left\{\varepsilon_{0}\right\}[A]\left\{\varepsilon_{0}\right\}^{T}+\left\{\varepsilon_{0}\right\}[B]\left\{\varepsilon_{1}\right\}^{T}+\left\{\varepsilon_{1}\right\}[B]\left\{\varepsilon_{0}\right\}^{T}\right. \\
\left.+\left\{\varepsilon_{1}\right\}[D]\left\{\varepsilon_{1}\right\}^{T}+\left\{\varepsilon_{0}^{*}\right\}\left[A^{*}\right]\left\{\varepsilon_{0}^{*}\right\}^{T}\right] d x d y
\end{gathered}
$$

where $R$ is the mid-surface area (Figure 1) and the stiffness coefficients $[35,36]$ are given by $\left(A_{i j}, B_{i j}, D_{i j}\right)=$ $\int_{-h / 2}^{h / 2} \bar{Q}_{i j}\left(1, z, z^{2}\right) d z(i, j=1,2,6), A_{i j}^{*}=\int_{-h / 2}^{h / 2} k_{i j} \bar{Q}_{i j} d z(i, j=$ $4,5) k_{i j}$ being the shear correction factors.

The strain energy corresponding to the elastic edge restraints is given by

$$
\begin{array}{r}
U_{t}=\frac{1}{2} \int_{0}^{a}\left[t_{1}^{w}\left(\left.w_{0}\right|_{y=0}\right)^{2}+t_{3}^{w}\left(\left.w_{0}\right|_{y=b}\right)^{2}+t_{1}^{v}\left(\left.v_{0}\right|_{y=0}\right)^{2}\right. \\
\left.+t_{3}^{v}\left(\left.v_{0}\right|_{y=b}\right)^{2}+r_{1}\left(\left.\phi_{y}\right|_{y=0}\right)^{2}+r_{3}\left(\left.\phi_{y}\right|_{y=b}\right)^{2}\right] d x \\
+\frac{1}{2} \int_{0}^{b}\left[t_{2}^{w}\left(\left.w_{0}\right|_{x=a}\right)^{2}+t_{4}^{w}\left(\left.w_{0}\right|_{x=0}\right)^{2}+t_{2}^{u}\left(\left.v_{0}\right|_{x=a}\right)^{2}\right. \\
\left.+t_{4}^{u}\left(\left.v_{0}\right|_{x=0}\right)^{2}+r_{2}\left(\left.\phi_{x}\right|_{x=a}\right)^{2}+r_{4}\left(\left.\phi_{x}\right|_{y=0}\right)^{2}\right] d y,
\end{array}
$$

where $t_{i}^{\bullet}(i=1, \ldots, 4$ and $\bullet=u, v, w)$ are the elastic translational coefficients and $r_{i}(i=1, \ldots, 4)$ are the elastic rotational coefficients.

The kinetic energy is expressed as

$$
\begin{gathered}
T=\frac{1}{2} \iint_{R}\left[I_{0}\left(\dot{u}_{0}^{2}+\dot{v}_{0}^{2}+\dot{w}_{0}^{2}\right)+2 I_{1}\left(\dot{u}_{0} \dot{\phi}_{x}+\dot{v}_{0} \dot{\phi}_{y}\right)\right. \\
\left.+I_{2}\left(\dot{\phi}_{x}^{2}+\dot{\phi}_{y}^{2}\right)\right] d x d y,
\end{gathered}
$$

being $I_{i}(i=0,1,2)$ the mass inertias of the plate defined as [35]

$$
I_{i}=\int_{-h / 2}^{h / 2} \rho^{(k)} z^{i} d z, \quad(i=0,1,2),
$$

where $\rho^{(k)}$ is the material density of the $k$-th layer.

\section{Application of the Ritz Method for the Free Vibration Analysis}

The Ritz method is applied to determine analytical approximate solutions for dynamical behavior of arbitrarily laminated plates resting on elastic supports. During free vibration, the displacements components are assumed split in 


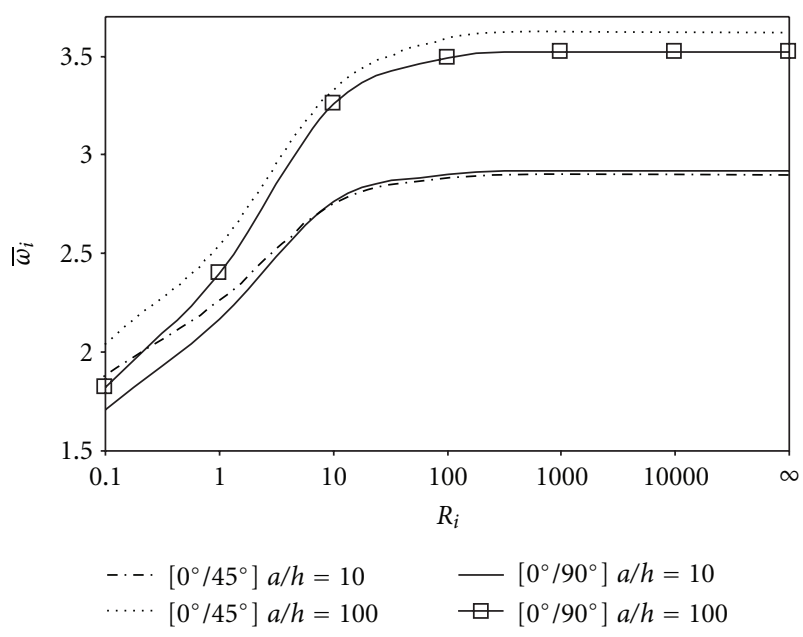

FIGURE 2: Variation of the fundamental frequency coefficient $\bar{\omega}$ with the rotational restraint parameter $R_{i}, T_{i}^{w}=T_{i}^{u}=T_{i}^{v}=\infty(i=$ $1, \ldots, 4)$ for square $\left[0^{\circ} / 45^{\circ}\right]$ and $\left[0^{\circ} / 90^{\circ}\right]$ carbon-epoxy (Table 1 ), with $k_{f}=0.6$.

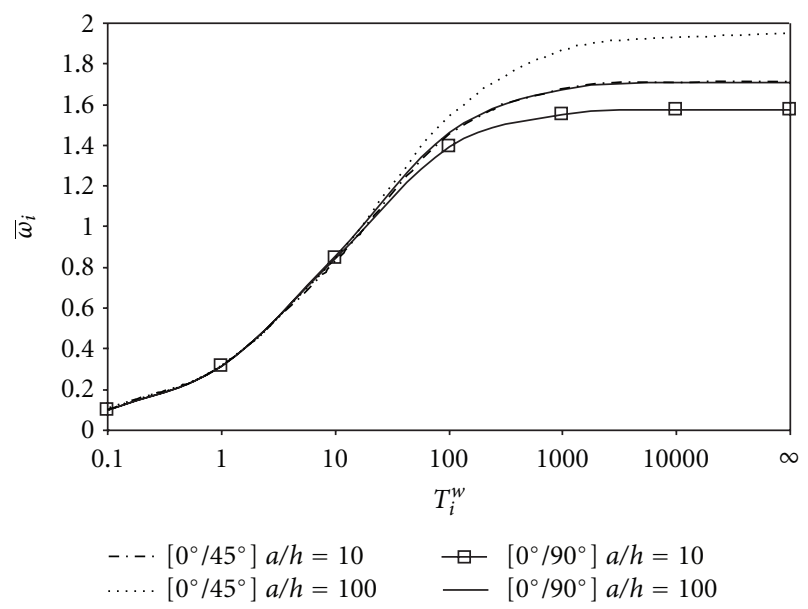

Figure 3: Variation of the fundamental frequency coefficient $\bar{\omega}$ with the translational restraint parameter $T_{i}^{w}, T_{i}^{u}=T_{i}^{v}=R_{i}=0(i=$ $1, \ldots, 4)$ for square $\left[0^{\circ} / 45^{\circ}\right]$ and $\left[0^{\circ} / 90^{\circ}\right]$ carbon-epoxy (Table 1 ), with $k_{f}=0.6$.

the spatial and temporal parts, being the last one periodic in time; that is,

$$
\begin{aligned}
& u_{0}(x, y, t)=U(x, y) \sin \omega t, \\
& v_{0}(x, y, t)=V(x, y) \sin \omega t, \\
& w_{0}(x, y, t)=W(x, y) \sin \omega t, \\
& \phi_{x}(x, y, t)=\Phi_{x}(x, y) \sin \omega t, \\
& \phi_{y}(x, y, t)=\Phi_{y}(x, y) \sin \omega t,
\end{aligned}
$$

where $\omega$ is the natural frequency in radian.

Putting these displacements into the energy functional components ((10) to (12)) the maximum values of the kinetic

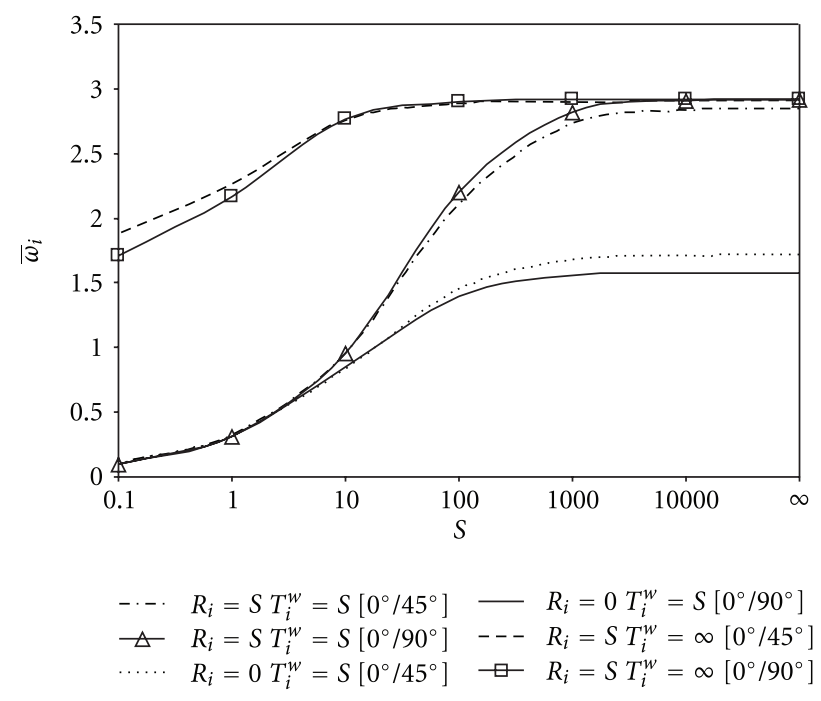

FIGURE 4: Variation of the fundamental frequency coefficient $\bar{\omega}$ with the translational and the rotational restraint parameters $T_{i}^{w}=$ $R_{i}, T_{i}^{u}=T_{i}^{v}=0(i=1, \ldots, 4)$ for square $\left[0^{\circ} / 45^{\circ}\right]$ and $\left[0^{\circ} / 90^{\circ}\right]$ carbon-epoxy (Table 1), with $k_{f}=0.6$ and $a / h=10$.

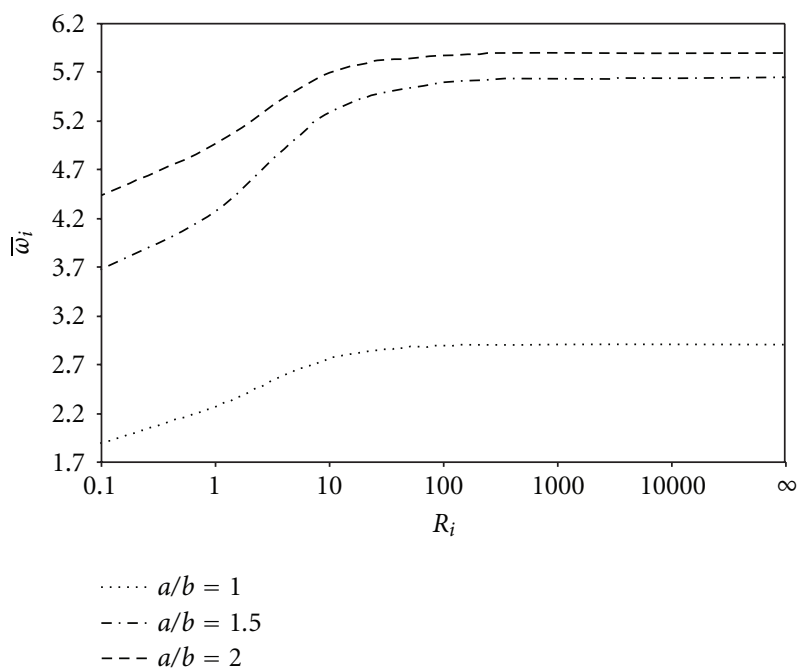

FIGURE 5: Variation of the fundamental frequency coefficient $\bar{\omega}$ with the rotational restraint parameter $R_{i}, T_{i}^{w}=T_{i}^{u}=T_{i}^{v}=\infty(i=$ $1, \ldots, 4)$ for different aspect ratios $\left[0^{\circ} / 45^{\circ}\right]$ carbon-epoxy (Table 1 ), with $k_{f}=0.6$.

energy $\left(T_{\max }\right)$ and the strain energies $\left(U_{p, \max }, U_{t, \max }\right)$ are derived. Then, the energy functional for free vibration of the laminated plate is given by

$$
\Pi=U_{p, \max }+U_{t, \max }-T_{\max },
$$

which is to be minimized according to the Ritz principle.

3.1. Boundary Conditions and Approximating Functions. There are some options when choosing the unknown functions of displacement components to apply the Ritz method. Particularly, the use of orthogonal polynomials as coordinate 


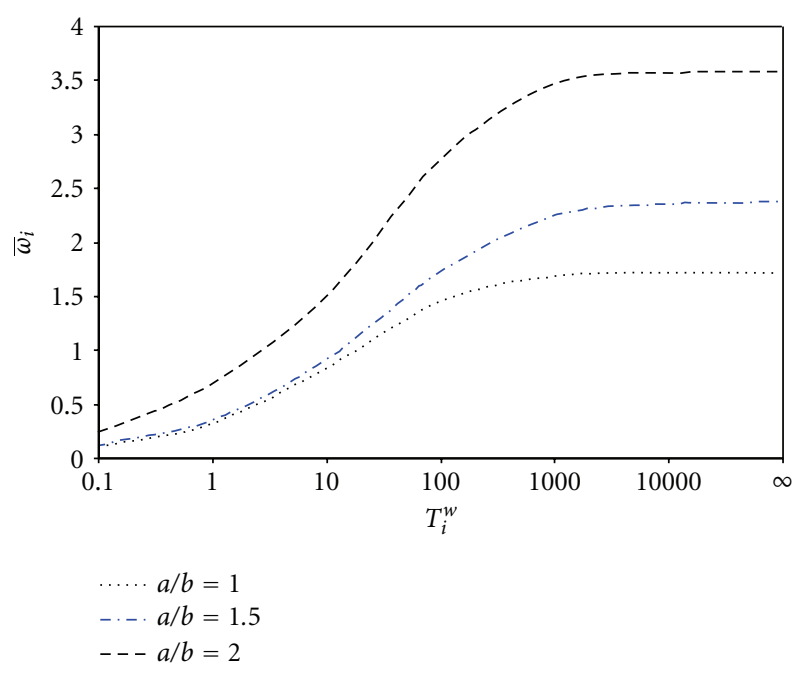

FIGURE 6: Variation of the fundamental frequency coefficient $\bar{\omega}$ with the translational restraint parameter $T_{i}^{w}, T_{i}^{u}=T_{i}^{v}=R_{i}=0(i=$ $1, \ldots, 4)$ for different aspect ratios $\left[0^{\circ} / 45^{\circ}\right]$ carbon-epoxy (Table 1 ), with $k_{f}=0.6$.

functions has important advantages related to numerical stability and fast convergence as has been demonstrated in previous works $[23,37,38]$, even for plates with complicated boundary conditions and high degree of anisotropy. For these reasons, in this work, the displacement components are expressed by sets of beam characteristic orthogonal polynomials $\left\{p_{i}^{(\cdot)}(x)\right\},\left\{q_{j}^{(\bullet)}(y)\right\},(\bullet)=u, v, w, \phi_{x}, \phi_{y}$, resulting in

$$
\begin{gathered}
U(x, y) \approx U_{M N}(x, y)=\sum_{i=1}^{M} \sum_{j=1}^{N} c_{i j}^{(u)} p_{i}^{(u)}(x) q_{j}^{(u)}(y), \\
V(x, y) \approx V_{M N}(x, y)=\sum_{i=1}^{M} \sum_{j=1}^{N} c_{i j}^{(v)} p_{i}^{(v)}(x) q_{j}^{(v)}(y), \\
W(x, y) \approx W_{M N}(x, y)=\sum_{i=1}^{M} \sum_{j=1}^{N} c_{i j}^{(w)} p_{i}^{(w)}(x) q_{j}^{(w)}(y), \\
\Phi_{x} \approx \Phi_{x M N}(x, y)=\sum_{i=1}^{N} \sum_{j=1}^{M} c_{i j}^{\left(\phi_{x}\right)} p_{i}^{\left(\phi_{x}\right)}(x) q_{j}^{\left(\phi_{x}\right)}(y), \\
\Phi_{y} \approx \Phi_{y_{M N}}(x, y)=\sum_{i=1}^{N} \sum_{j=1}^{M} c_{i j}^{\left(\phi_{y}\right)} p_{i}^{\left(\phi_{y}\right)}(x) q_{j}^{\left(\phi_{y}\right)}(y),
\end{gathered}
$$

where $c_{i j}^{(u)}, c_{i j}^{(v)}, c_{i j}^{(w)}, c_{i j}^{\left(\phi_{x}\right)}, c_{i j}^{\left(\phi_{y}\right)}$ are the unknown coefficients, and $M, N$ are the numbers of polynomials in each coordinate.

The procedure for the construction of the orthogonal polynomials has been developed by Bhat [39]. The first members of the sets, $p_{1}^{(\bullet)}(x)$ and $q_{1}^{(\bullet)}(y)(\bullet)=u, v, w, \phi_{x}, \phi_{y}$ are obtained as the simplest polynomials that satisfy all

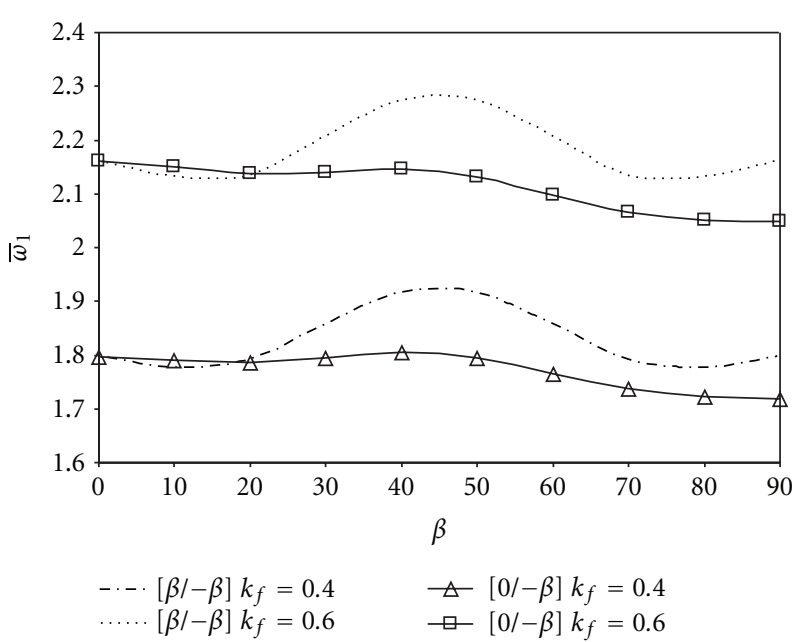

FIGURE 7: Effect of the fiber orientation on the first vibration frequency coefficient $\bar{\omega}_{1}$, for two different fiber volume fraction $k_{f}$ with $C_{1} C_{1} C_{1} C_{1}$ boundary condition and $a / h=10$.

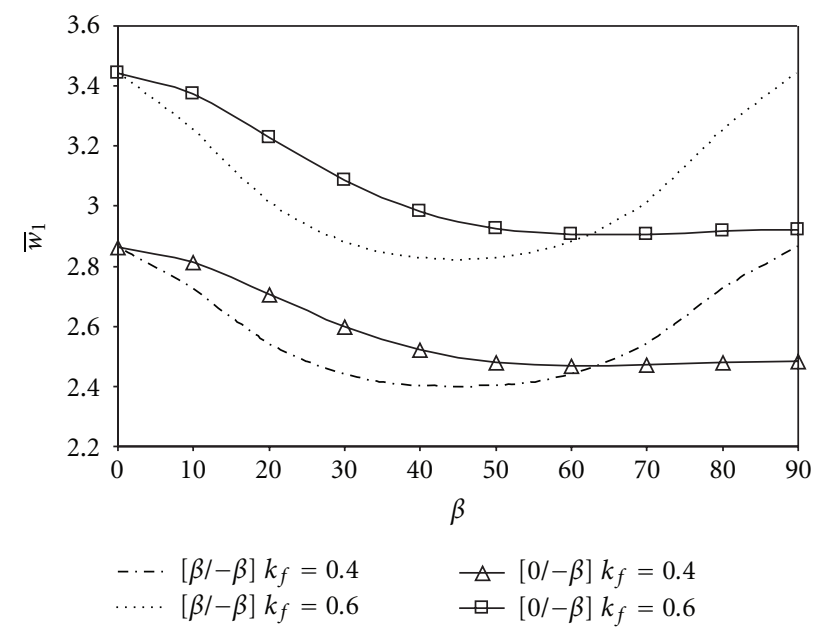

Figure 8: Effect of the fiber orientation on the first vibration frequency coefficient $\bar{\omega}_{1}$, for two different fiber volume fraction $k_{f}$ with $S_{1} S_{1} S_{1} S_{1}$ boundary condition and $a / h=10$.

the geometrical boundary conditions of the plate in their respective $x$ and $y$ directions. The higher members of each set are constructed by employing the Gram-Schmidt orthogonalization procedure. The coefficients of the polynomials are chosen in such a way as to make the polynomials orthonormal. However, the functions $p_{k}^{(\bullet)}(x)$ and $q_{k}^{(\bullet)}(y)$ for $(\bullet)=\phi_{x}, \phi_{y}$ are obtained from relative rotation conditions starting from polynomials of an order lower than the chosen for the transversal displacements and then applying the sequence of Gram-Schmidt orthogonalization procedure. This particular choice is made to avoid the overestimation of the rate of elastic energy due to the shear respect to the rate due to the bending. This concept has been applied by Auciello and Ercolano [40], to Timoshenko beams, to avoid 
TABLE 2: Notations for various combinations of boundary conditions, in which $n$ and $s$ indicate the directions normal and tangential to the respective plate edges.

\begin{tabular}{lcccc}
\hline & & \multicolumn{2}{c}{ In-plane constraints } \\
Transverse constraints & $u_{n}=0, u_{s}=0$ & $N_{n}=0, u_{s}=0$ & $u_{n}=0, N_{n s}=0$ & $N_{n}=0, N_{n s}=0$ \\
\hline Clamped: $w=0 ; \phi_{n}=0$ & $C_{1}$ & $C_{2}$ & $C_{3}$ & $C_{4}$ \\
Simply supported: $w=0 ; M_{n}=0 ; \phi_{s}=0$ & $S_{1}$ & $S_{2}$ & $S_{3}$ & $S_{4}$ \\
Free: $M_{n}=0 ; M_{n s}=0 ; Q_{n}=0$ & $F_{1}$ & $F_{2}$ & $F_{3}$ & $F_{4}$ \\
\hline
\end{tabular}

TABLE 3: Convergence study of frequencies $\omega_{i}^{*}=\omega_{i} a^{2} \sqrt{\rho /\left(E_{2} h^{2}\right)}$ for a two-layered $\left[0^{\circ} / 45^{\circ}\right]$ square plate. $E_{1} / E_{2}=25, G_{12}=G_{13}=$ $0.5 E_{2}, G_{23}=0.2 E_{2}, v_{12}=0.25$.

\begin{tabular}{|c|c|c|c|c|c|c|c|}
\hline \multirow{2}{*}{$a / h$} & \multirow{2}{*}{$\begin{array}{c}M, N \\
(M=N)\end{array}$} & \multicolumn{6}{|c|}{ Mode sequence number } \\
\hline & & 1 & 2 & 3 & 4 & 5 & 6 \\
\hline \multirow{8}{*}{10} & 4 & 15.487 & 23.582 & 30.182 & 35.243 & 42.217 & 49.098 \\
\hline & 5 & 15.480 & 23.401 & 30.005 & 33.514 & 38.099 & 44.303 \\
\hline & 6 & 15.478 & 23.359 & 29.960 & 33.217 & 37.825 & 43.331 \\
\hline & 7 & 15.478 & 23.356 & 29.957 & 33.112 & 37.691 & 42.997 \\
\hline & 8 & 15.478 & 23.356 & 29.956 & 33.104 & 37.679 & 42.901 \\
\hline & 9 & 15.478 & 23.356 & 29.956 & 33.103 & 37.676 & 42.889 \\
\hline & 10 & 15.478 & 23.356 & 29.956 & 33.103 & 37.675 & 42.887 \\
\hline & Shi et al. [5] & 15.504 & 23.399 & 29.991 & 33.170 & 37.740 & 42.973 \\
\hline \multirow{8}{*}{20} & 4 & 19.248 & 30.947 & 42.338 & 50.788 & 71.618 & 81.985 \\
\hline & 5 & 19.227 & 30.415 & 41.788 & 46.288 & 54.225 & 64.750 \\
\hline & 6 & 19.221 & 30.279 & 41.586 & 45.434 & 53.531 & 62.080 \\
\hline & 7 & 19.219 & 30.271 & 41.572 & 45.047 & 53.090 & 61.032 \\
\hline & 8 & 19.219 & 30.268 & 41.569 & 45.016 & 53.047 & 60.655 \\
\hline & 9 & 19.218 & 30.267 & 41.569 & 45.008 & 53.032 & 60.600 \\
\hline & 10 & 19.218 & 30.267 & 41.568 & 45.007 & 53.030 & 60.587 \\
\hline & Shi et al. [5] & 19.350 & 30.490 & 41.769 & 45.400 & 53.385 & 61.035 \\
\hline \multirow{8}{*}{100} & 4 & 21.348 & 36.366 & 52.130 & 65.773 & 298.228 & 304.052 \\
\hline & 5 & 21.314 & 35.002 & 50.893 & 56.783 & 68.251 & 86.403 \\
\hline & 6 & 21.291 & 34.676 & 50.155 & 54.927 & 66.919 & 79.733 \\
\hline & 7 & 21.289 & 34.660 & 50.124 & 53.854 & 65.602 & 76.972 \\
\hline & 8 & 21.288 & 34.655 & 50.107 & 53.792 & 65.504 & 75.800 \\
\hline & 9 & 21.288 & 34.654 & 50.106 & 53.757 & 65.449 & 75.631 \\
\hline & 10 & 21.288 & 34.654 & 50.106 & 53.754 & 65.444 & 75.553 \\
\hline & Shi et al. [5] & 21.802 & 35.692 & 51.304 & 55.298 & 67.257 & 77.843 \\
\hline
\end{tabular}

TABLE 4: Comparison of fundamental frequency coefficient $\omega_{i}^{*}=\omega_{i} a^{2} \sqrt{\rho /\left(E_{2} h^{2}\right)}$ for a four layered $\left[45^{\circ} /-45^{\circ} / 45^{\circ} /-45^{\circ}\right]$ plate with different aspect ratios $a / b . E_{1} / E_{2}=40, G_{12}=0.6 E_{2}, G_{13}=G_{23}=0.5 E_{2}, v_{12}=0.25$.

\begin{tabular}{llccccccc}
\hline$a / h$ & & \multicolumn{5}{c}{$a / b$} \\
& & 0.2 & 0.6 & 0.8 & 1 & 1.2 & 1.6 & 2 \\
10 & Present & 9.013 & 13.02 & 15.74 & 18.62 & 21.59 & 27.66 & 34.57 \\
& Alibeigloo et al. [31] & 8.559 & 12.565 & 15.187 & 17.983 & 20.895 & 27.031 & 33.634 \\
& Redy [32] & 8.724 & 12.965 & 15.712 & 18.609 & 21.567 & 27.736 & 34.247 \\
30 & Present & 9.965 & 15.409 & 19.293 & 23.638 & 28.377 & 39.062 & 51.480 \\
& Alibeigloo et al. [31] & 9.420 & 14.790 & 18.487 & 22.637 & 27.200 & 37.534 & 49.499 \\
& Redy [32] & 9.667 & 15.385 & 19.304 & 23.676 & 28.381 & 38.940 & 51.132 \\
50 & Present & 10.056 & 15.66 & 19.70 & 24.25 & 29.25 & 40.70 & 54.25 \\
& Alibeigloo et al. [31] & 9.5016 & 15.0261 & 18.8586 & 23.195 & 28.003 & 39.05 & 52.686 \\
& Redy [32] & 9.816 & 15.689 & 19.759 & 24.343 & 29.321 & 40.653 & 53.989 \\
\hline
\end{tabular}


TABle 5: (a) Frequency parameters $\bar{\omega}_{i}$ for $\left[0^{\circ} / 45^{\circ}\right]$ and $\left[0^{\circ} / 90^{\circ}\right]$ carbon-epoxy AS4-3501-6 (Table 1), with different translational restraint parameter $T_{i}^{w}, T_{i}^{u}=T_{i}^{v}=R_{i}=0(i=1, \ldots, 4)$, and $a / h=10$. (b) Frequency parameters $\bar{\omega}_{i}$ for $\left[0^{\circ} / 45^{\circ}\right]$ and $\left[0^{\circ} / 90^{\circ}\right]$ carbon-epoxy AS4-3501-6 (Table 1), with different translational restraint parameter $T_{i}^{w}, T_{i}^{u}=T_{i}^{v}=R_{i}=0(i=1, \ldots, 4)$, and $a / h=100$.

(a)

\begin{tabular}{|c|c|c|c|c|c|c|c|c|}
\hline \multirow{2}{*}{$k_{f}$} & \multirow{2}{*}{ Mode } & \multicolumn{7}{|c|}{ Translational restraint parameter $T_{i}^{w}$} \\
\hline & & 0.1 & 1 & 10 & 100 & 1000 & 10000 & $1.00 E+10$ \\
\hline \multicolumn{9}{|c|}{$a / h=10$} \\
\hline \multicolumn{9}{|c|}{$\left[0^{\circ} / 45^{\circ}\right]$} \\
\hline \multirow{4}{*}{0.2} & 1 & 0.060 & 0.187 & 0.520 & 0.969 & 1.161 & 1.191 & 1.195 \\
\hline & 2 & 0.085 & 0.266 & 0.803 & 1.827 & 2.380 & 2.470 & 2.481 \\
\hline & 3 & 0.085 & 0.267 & 0.822 & 2.079 & 2.930 & 3.063 & 3.078 \\
\hline & 4 & 0.754 & 0.810 & 1.224 & 2.609 & 3.776 & 4.004 & 4.032 \\
\hline \multirow{4}{*}{0.4} & 1 & 0.083 & 0.256 & 0.689 & 1.219 & 1.419 & 1.448 & 1.452 \\
\hline & 2 & 0.117 & 0.367 & 1.083 & 2.284 & 2.829 & 2.912 & 2.922 \\
\hline & 3 & 0.117 & 0.368 & 1.125 & 2.723 & 3.638 & 3.767 & 3.782 \\
\hline & 4 & 0.890 & 0.978 & 1.590 & 3.325 & 4.530 & 4.735 & 4.759 \\
\hline \multirow{4}{*}{0.6} & 1 & 0.101 & 0.310 & 0.824 & 1.443 & 1.671 & 1.705 & 1.709 \\
\hline & 2 & 0.142 & 0.445 & 1.303 & 2.685 & 3.290 & 3.382 & 3.393 \\
\hline & 3 & 0.142 & 0.447 & 1.364 & 3.274 & 4.342 & 4.492 & 4.509 \\
\hline & 4 & 1.040 & 1.151 & 1.903 & 3.936 & 5.292 & 5.517 & 5.543 \\
\hline \multirow{6}{*}{0.2} & {$\left[0^{\circ} / 90^{\circ}\right]$} & & & & & & & \\
\hline & 1 & 0.060 & 0.188 & 0.528 & 0.942 & 1.084 & 1.104 & 1.106 \\
\hline & 2 & 0.085 & 0.267 & 0.814 & 1.970 & 2.657 & 2.756 & 2.768 \\
\hline & 3 & 0.085 & 0.267 & 0.814 & 1.970 & 2.657 & 2.756 & 2.768 \\
\hline & 4 & 0.628 & 0.697 & 1.164 & 2.642 & 3.708 & 3.888 & 3.909 \\
\hline & 1 & 0.083 & 0.258 & 0.705 & 1.181 & 1.321 & 1.340 & 1.342 \\
\hline \multirow{3}{*}{0.4} & 2 & 0.117 & 0.368 & 1.110 & 2.546 & 3.251 & 3.344 & 3.355 \\
\hline & 3 & 0.117 & 0.368 & 1.110 & 2.546 & 3.251 & 3.344 & 3.355 \\
\hline & 4 & 0.750 & 0.858 & 1.540 & 3.424 & 4.519 & 4.675 & 4.675 \\
\hline \multirow{4}{*}{0.6} & 1 & 0.101 & 0.313 & 0.847 & 1.395 & 1.553 & 1.574 & 1.577 \\
\hline & 2 & 0.142 & 0.446 & 1.343 & 3.035 & 3.829 & 3.932 & 3.944 \\
\hline & 3 & 0.142 & 0.446 & 1.343 & 3.035 & 3.829 & 3.932 & 3.944 \\
\hline & 4 & 0.910 & 1.040 & 1.864 & 4.089 & 5.329 & 5.514 & 5.536 \\
\hline \multicolumn{9}{|c|}{ (b) } \\
\hline \multirow{2}{*}{$k_{f}$} & \multirow{2}{*}{ Mode } & \multicolumn{7}{|c|}{ Translational restraint parameter $T_{i}^{w}$} \\
\hline & & 0.1 & 1 & 10 & 100 & 1000 & 10000 & $1.00 E+10$ \\
\hline \multicolumn{9}{|c|}{$a / h=100$} \\
\hline \multicolumn{9}{|c|}{$\left[0^{\circ} / 45^{\circ}\right]$} \\
\hline \multirow{4}{*}{0.2} & 1 & 0.060 & 0.187 & 0.525 & 1.014 & 1.276 & 1.329 & 1.340 \\
\hline & 2 & 0.085 & 0.268 & 0.813 & 1.928 & 2.708 & 2.881 & 2.908 \\
\hline & 3 & 0.085 & 0.269 & 0.832 & 2.214 & 3.489 & 3.771 & 3.815 \\
\hline & 4 & 0.804 & 0.858 & 1.266 & 2.774 & 4.519 & 5.027 & 5.098 \\
\hline \multirow{4}{*}{0.4} & 1 & 0.083 & 0.256 & 0.697 & 1.292 & 1.577 & 1.633 & 1.646 \\
\hline & 2 & 0.117 & 0.369 & 1.099 & 2.445 & 3.269 & 3.440 & 3.468 \\
\hline & 3 & 0.117 & 0.370 & 1.142 & 2.952 & 4.444 & 4.746 & 4.794 \\
\hline & 4 & 0.947 & 1.032 & 1.642 & 3.588 & 5.531 & 6.011 & 6.073 \\
\hline \multirow{4}{*}{0.6} & 1 & 0.101 & 0.310 & 0.835 & 1.531 & 1.859 & 1.925 & 1.940 \\
\hline & 2 & 0.142 & 0.447 & 1.324 & 2.880 & 3.804 & 3.995 & 4.028 \\
\hline & 3 & 0.143 & 0.450 & 1.385 & 3.555 & 5.304 & 5.654 & 5.711 \\
\hline & 4 & 1.104 & 1.210 & 1.962 & 4.255 & 6.457 & 6.980 & 7.046 \\
\hline
\end{tabular}


(b) Continued.

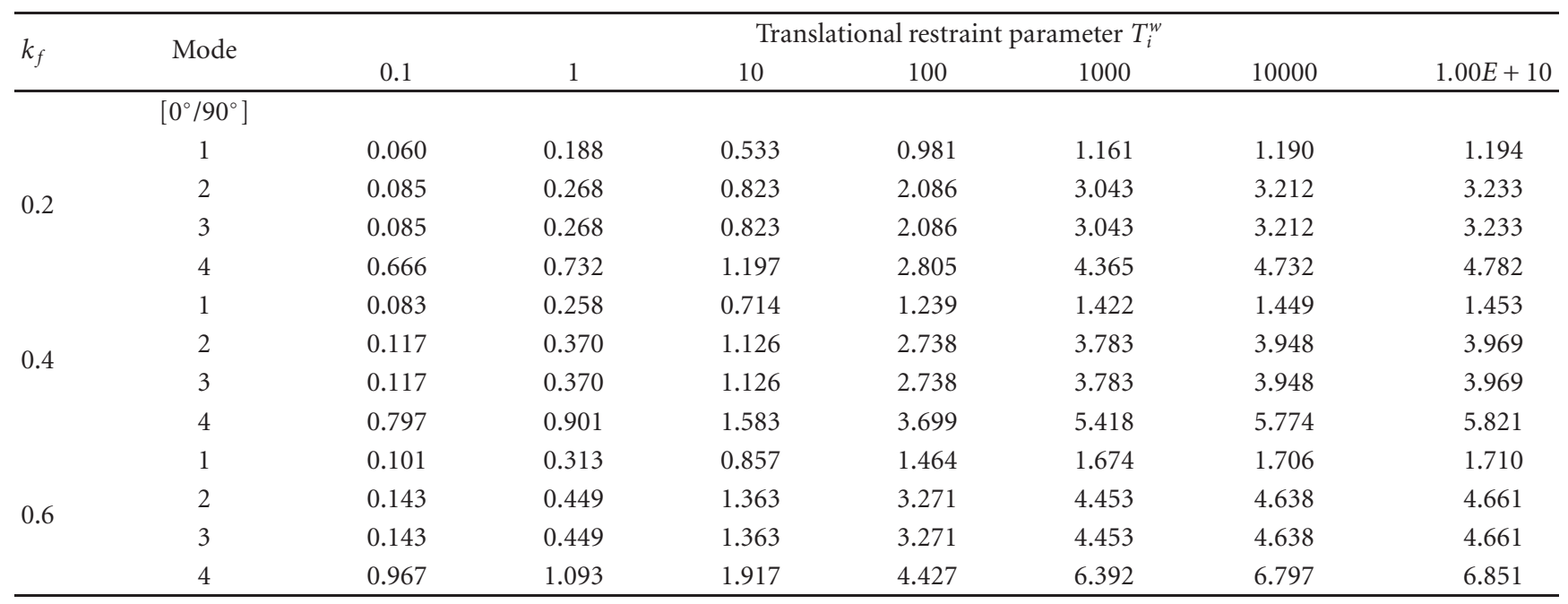

the shear locking effect and is extended here for laminated plates.

The classical boundary conditions considered in this study are depicted in Table 2. By keeping in mind that in the Ritz method only the geometric boundary conditions need to be satisfied, it is possible to work with any sets of required edge boundary condition and also is very simple the consideration of elastically restrained edges where there are not essential boundary conditions to satisfy.

Upon inserting the displacement forms (16) into the energy functional of the system (15), the minimization with respect to the coefficients of the displacement functions is given by

$$
\begin{gathered}
\frac{\partial \Pi}{\partial c_{i j}^{(u)}}=0, \quad \frac{\partial \Pi}{\partial c_{i j}^{(v)}}=0, \quad \frac{\partial \Pi}{\partial c_{i j}^{(w)}}=0, \\
\frac{\partial \Pi}{\partial c_{i j}^{\left(\phi_{x}\right)}}=0, \quad \frac{\partial \Pi}{\partial c_{i j}^{\left(\phi_{y}\right)}}=0 .
\end{gathered}
$$

From (17) a set of algebraic simultaneous equations is obtained. The number of these equations becomes $5 \times M \times N$. The algebraic equations obtained are given as follows, in the form of the generalized eigenvalue problem:

$$
\left(\mathbf{K}-\omega^{2} \mathbf{M}\right)\{\mathbf{C}\}=\{\mathbf{0}\},
$$

where $\mathbf{K}$ and $\mathbf{M}$ are stiffness and inertia matrices, respectively (their expressions are given in the Appendix, $\{\mathbf{C}\}$ contains the unknown coefficients of (16).

For a nontrivial solution, the eigenvalues which make the determinant equal to zero, correspond to the free vibration frequencies.

\section{Verification of the Formulation and Numerical Applications}

4.1. General Description. The variational algorithm developed in this paper was programmed in Fortran language and used for the free vibration analysis of generally laminated thin and moderately thick laminated plates having different geometric parameters, stacking sequences, material properties, fiber volume fractions, and boundary conditions. The examples considered in this study are confined to laminates with layers of equal thickness, even though the procedure was formulated for plies with arbitrary thickness. In all cases the shear correction factor was taken a 5/6.

Let us introduce the terminology to be used throughout the remainder of the paper for describing the boundary conditions of the considered plates. The designation $C_{i} S_{i} F_{i} S_{i}$, for example, identifies a plate with edges (1) clamped, (2) simply supported, (3) free, and (4) simply supported (see Figure 1) the subscript $i(i=1, \ldots, 4)$ identifies the inplane constraints according to Table 2 . When the edges are elastically restrained against rotation or translation, the following nondimensional restraint parameters are used

$$
\begin{gathered}
T_{i}^{\bullet}=\frac{a^{3} t_{i}^{\bullet}}{D_{0}}, \quad(i=1, \ldots, 4 \text { and } \bullet=u, v, w), \\
R_{i}=\frac{r_{i} a}{D_{0}}, \quad(i=1, \ldots, 4),
\end{gathered}
$$

where $D_{0}=E_{1} h^{3} / 12\left(1-v_{12} \nu_{21}\right)$.

The main purposes of the numerical applications presented in this section are twofold. One is to demonstrate the accuracy, the flexibility, and the efficiency of the proposed method and the other is to produce some results which may be regarded as benchmark solutions for other academic research workers and design engineers.

4.2. Validation and Convergence Studies. The accuracy and reliability of the results obtained with the present approach are next demonstrated by comparing them with some selected values published by Shi et al. [5] for moderately thick $(a / h=10,20)$ and thin $(a / h=100)$ arbitrarily clamped laminated plates. The comparison presented in Table 3 authenticates the validity of the present method for arbitrarily laminated plates. Very close agreement for the first 
TABLe 6: (a) Frequency parameters $\bar{\omega}_{i}$ for $\left[0^{\circ} / 45^{\circ}\right]$ and $\left[0^{\circ} / 90^{\circ}\right]$ carbon-epoxy AS4-3501-6 (Table 1), with different rotational restraint parameter $R_{i}, T_{i}^{w}=T_{i}^{u}=T_{i}^{v}=\infty(i=1, . ., 4)$, and $a / h=10$. (b) Frequency parameters $\bar{\omega}_{i}$ for $\left[0^{\circ} / 45^{\circ}\right]$ and $\left[0^{\circ} / 90^{\circ}\right]$ carbon-epoxy AS4-3501-6 (Table 1), with different rotational restraint parameter $R_{i}, T_{i}^{w}=T_{i}^{u}=T_{i}^{v}=\infty(i=1, . ., 4)$, and $a / h=100$.

(a)

\begin{tabular}{|c|c|c|c|c|c|c|c|c|}
\hline \multirow{2}{*}{$k_{f}$} & \multirow{2}{*}{ Mode } & \multicolumn{7}{|c|}{ Rotational restraint parameter $R_{i}$} \\
\hline & & 0.1 & 1 & 10 & 100 & 1000 & 10000 & $1.00 E+10$ \\
\hline \multicolumn{9}{|c|}{$a / h=10$} \\
\hline \multicolumn{9}{|c|}{$\left[0^{\circ} / 45^{\circ}\right]$} \\
\hline \multirow{4}{*}{0.2} & 1 & 1.461 & 1.623 & 1.943 & 2.056 & 2.071 & 2.072 & 2.072 \\
\hline & 2 & 2.709 & 2.903 & 3.268 & 3.390 & 3.406 & 3.407 & 3.407 \\
\hline & 3 & 3.350 & 3.497 & 3.861 & 4.010 & 4.030 & 4.032 & 4.032 \\
\hline & 4 & 4.322 & 4.477 & 4.818 & 4.951 & 4.969 & 4.971 & 4.971 \\
\hline \multirow{4}{*}{0.4} & 1 & 1.837 & 2.029 & 2.371 & 2.483 & 2.497 & 2.498 & 2.498 \\
\hline & 2 & 3.249 & 3.493 & 3.875 & 3.988 & 4.002 & 4.003 & 4.003 \\
\hline & 3 & 4.112 & 4.302 & 4.709 & 4.854 & 4.872 & 4.874 & 4.874 \\
\hline & 4 & 5.129 & 5.333 & 5.700 & 5.823 & 5.838 & 5.840 & 5.840 \\
\hline \multirow{4}{*}{0.6} & 1 & 2.182 & 2.408 & 2.803 & 2.931 & 2.947 & 2.949 & 2.949 \\
\hline & 2 & 3.799 & 4.090 & 4.527 & 4.654 & 4.669 & 4.671 & 4.671 \\
\hline & 3 & 4.884 & 5.119 & 5.611 & 5.783 & 5.804 & 5.806 & 5.807 \\
\hline & 4 & 5.987 & 6.239 & 6.672 & 6.812 & 6.830 & 6.832 & 6.832 \\
\hline \multirow{6}{*}{0.2} & {$\left[0^{\circ} / 90^{\circ}\right]$} & & & & & & & \\
\hline & 1 & 1.386 & 1.562 & 1.916 & 2.034 & 2.048 & 2.050 & 2.050 \\
\hline & 2 & 2.901 & 3.110 & 3.561 & 3.719 & 3.738 & 3.740 & 3.741 \\
\hline & 3 & 2.901 & 3.110 & 3.561 & 3.719 & 3.738 & 3.740 & 3.741 \\
\hline & 4 & 4.052 & 4.287 & 4.764 & 4.970 & 4.994 & 4.996 & 4.996 \\
\hline & 1 & 1.755 & 1.969 & 2.352 & 2.468 & 2.482 & 2.483 & 2.483 \\
\hline \multirow{3}{*}{0.4} & 2 & 3.532 & 3.814 & 4.321 & 4.473 & 4.491 & 4.493 & 4.493 \\
\hline & 3 & 3.532 & 3.814 & 4.321 & 4.473 & 4.491 & 4.493 & 4.493 \\
\hline & 4 & 4.932 & 5.218 & 5.745 & 5.949 & 5.971 & 5.973 & 5.973 \\
\hline \multirow{4}{*}{0.6} & 1 & 2.090 & 2.340 & 2.776 & 2.905 & 2.920 & 2.922 & 2.922 \\
\hline & 2 & 4.167 & 4.511 & 5.102 & 5.272 & 5.292 & 5.294 & 5.295 \\
\hline & 3 & 4.167 & 4.511 & 5.102 & 5.272 & 5.292 & 5.294 & 5.295 \\
\hline & 4 & 5.833 & 6.179 & 6.790 & 7.021 & 7.045 & 7.047 & 7.048 \\
\hline \multicolumn{9}{|c|}{ (b) } \\
\hline \multirow{2}{*}{$k_{f}$} & \multirow{2}{*}{ Mode } & \multicolumn{7}{|c|}{ Rotational restraint parameter $R_{i}$} \\
\hline & & 0.1 & 1 & 10 & 100 & 1000 & 10000 & $1.00 E+10$ \\
\hline \multicolumn{9}{|c|}{$a / h=100$} \\
\hline \multicolumn{9}{|c|}{$\left[0^{\circ} / 45^{\circ}\right]$} \\
\hline \multirow{4}{*}{0.2} & 1 & 1.598 & 1.814 & 2.318 & 2.534 & 2.564 & 2.567 & 2.567 \\
\hline & 2 & 3.108 & 3.410 & 4.115 & 4.415 & 4.457 & 4.461 & 4.462 \\
\hline & 3 & 4.161 & 4.421 & 5.275 & 5.759 & 5.831 & 5.839 & 5.840 \\
\hline & 4 & 5.366 & 5.689 & 6.611 & 7.100 & 7.173 & 7.181 & 7.181 \\
\hline \multirow{4}{*}{0.4} & 1 & 2.044 & 2.316 & 2.901 & 3.135 & 3.166 & 3.169 & 3.170 \\
\hline & 2 & 3.783 & 4.185 & 4.997 & 5.311 & 5.353 & 5.358 & 5.358 \\
\hline & 3 & 5.265 & 5.627 & 6.699 & 7.240 & 7.317 & 7.325 & 7.326 \\
\hline & 4 & 6.450 & 6.911 & 8.018 & 8.523 & 8.594 & 8.601 & 8.602 \\
\hline \multirow{4}{*}{0.6} & 1 & 2.428 & 2.748 & 3.423 & 3.689 & 3.725 & 3.729 & 3.729 \\
\hline & 2 & 4.418 & 4.896 & 5.821 & 6.171 & 6.217 & 6.222 & 6.223 \\
\hline & 3 & 6.250 & 6.692 & 7.967 & 8.593 & 8.682 & 8.691 & 8.692 \\
\hline & 4 & 7.498 & 8.058 & 9.337 & 9.897 & 9.974 & 9.983 & 9.983 \\
\hline
\end{tabular}


(b) Continued.

\begin{tabular}{|c|c|c|c|c|c|c|c|c|}
\hline \multirow{2}{*}{$k_{f}$} & \multirow{2}{*}{ Mode } & \multicolumn{7}{|c|}{ Rotational restraint parameter $R_{i}$} \\
\hline & & 0.1 & 1 & 10 & 100 & 1000 & 10000 & $1.00 E+10$ \\
\hline & {$\left[0^{\circ} / 90^{\circ}\right]$} & & & & & & & \\
\hline \multirow{4}{*}{0.2} & 1 & 1.493 & 1.719 & 2.223 & 2.413 & 2.437 & 2.440 & 2.440 \\
\hline & 2 & 3.396 & 3.720 & 4.583 & 4.960 & 5.010 & 5.016 & 5.016 \\
\hline & 3 & 3.396 & 3.720 & 4.583 & 4.960 & 5.010 & 5.016 & 5.016 \\
\hline & 4 & 5.036 & 5.390 & 6.396 & 6.966 & 7.039 & 7.047 & 7.048 \\
\hline \multirow{4}{*}{0.4} & 1 & 1.917 & 2.203 & 2.780 & 2.976 & 3.001 & 3.003 & 3.003 \\
\hline & 2 & 4.202 & 4.665 & 5.725 & 6.122 & 6.172 & 6.178 & 6.178 \\
\hline & 3 & 4.202 & 4.665 & 5.725 & 6.122 & 6.172 & 6.178 & 6.178 \\
\hline & 4 & 6.173 & 6.688 & 7.937 & 8.560 & 8.634 & 8.641 & 8.642 \\
\hline \multirow{4}{*}{0.6} & 1 & 2.286 & 2.621 & 3.277 & 3.494 & 3.521 & 3.523 & 3.524 \\
\hline & 2 & 4.952 & 5.515 & 6.745 & 7.185 & 7.241 & 7.247 & 7.247 \\
\hline & 3 & 4.952 & 5.515 & 6.745 & 7.185 & 7.241 & 7.247 & 7.247 \\
\hline & 4 & 7.297 & 7.918 & 9.364 & 10.060 & 10.141 & 10.149 & 10.150 \\
\hline
\end{tabular}

sixth nondimensional frequencies $\omega_{i}^{*}=\omega_{i} a^{2} \sqrt{\rho /\left(E_{2} h^{2}\right)}$ is obtained for all cases and display monotonic convergence tendency to constant values. For thick plates, as shown in Table 3, as number of $N$ and $M$ is increased from 7 to 10 , the frequency parameter decreases merely $0.002 \%$ for the first mode and $0.26 \%$ for the sixth. For thin plates the relative decreases of the frequency parameters are $0.004 \%$ for the first mode and $1.88 \%$ for the sixth as the numbers of polynomials $M, N$ are increased from 7 to 10 , exhibiting slower convergence rate than that of moderately thick plates. Consequently the number of beam characteristic polynomials used in the following computations for thin and thick plates is chosen as $M=N=7$.

The validation of the proposed methodology for different aspect ratios $(a / b)$ is presented in Table 4, showing a good agreement with Alibeigloo et al. [31] and Reddy [32].

4.3. Numerical Results and Discussion. Several examples including new results for arbitrarily laminated plates with elastically restrained edges are presented in this section. The elastic properties of the composite materials used here are those shown in Table 1. The influence of different values of fiber volume ratios $\left(k_{f}\right)$ is analyzed in several figures and tables.

Values of the first four frequency parameters $\bar{\omega}_{i}=\omega_{i}\left(a^{2} /\right.$ h) $\sqrt{\rho / E_{f 1}}$ for square thick $(a / h=10)$ and thin $(a / h=100)$ unsymmetric laminated plates are shown for increasing values of the translational restraint parameter $T_{i}^{w}$, in Tables 5(a) and 5(b). Moreover, the influence of rotational restraint parameter $R_{i}$ in the free vibration frequency coefficients is shown in Tables 6(a) and 6(b).

In Figures $2-4$ the fundamental frequency coefficients $\bar{\omega}$ corresponding to two laminated square plates are plotted against the restraint parameters $R_{i}$ and $T_{i}^{w}$. Figure 2 shows the variation of $\bar{\omega}$ for various values of the rotational restraint $R_{i}$, while Figure 3 shows the variation of $\bar{\omega}$ for various values of the translational restraint $T_{i}^{w}$. A major increase of frequency occurs when the elastic restraint values are in the interval $0.1-50$. Figure 4 shows the variation of $\bar{\omega}$ for various values of the rotational and translational restraint parameters: (a) $R_{i}=0, T_{i}^{w}=S$; (b) $R_{i}=S, T_{i}^{w}=\infty$, and (c) $R_{i}=T_{i}^{w}=S$. The obtained curves illustrate the restraint parameters intervals for which the frequency coefficient $\bar{\omega}$ is sensitive to $R_{i}$ and $T_{i}^{w}$.

To asses the influence of the aspects ratio $a / b$ in the laminated plate response, values of the first four frequency parameters $\bar{\omega}_{i}=\omega_{i}\left(a^{2} / h\right) \sqrt{\rho / E_{f 1}}$ for rectangular thick $(a / h=10)$ unsymmetric laminated plates are shown, for increasing values of the translational restraint parameter $T_{i}^{w}$ (Table $7(\mathrm{a})$ ) and the rotational restraint parameter $R_{i}$ (Table $7(\mathrm{~b})$ ) considering $a / b=1.5$ and $a / b=2$.

Figure 5 shows the variation of $\bar{\omega}$ for various values of the rotational restraint $R_{i}$, while Figure 6 shows the variation of $\bar{\omega}$ for various values of the translational restraint $T_{i}^{w}$ for rectangular laminated plates.

To evaluate the effect of different fiber orientation angles $(\beta)$ and fiber volume fraction on the dynamic properties of the laminates, the variation of the first free vibration coefficient $\bar{\omega}_{1}$ is plotted in Figures 7 and 8, considering two lamination stacking sequences, $[\beta /-\beta]$ and $[0 / \beta]$. Two boundary conditions have been included, $C_{1} C_{1} C_{1} C_{1}$ in Figure 7 and $S_{1} S_{1} S_{1} S_{1}$ in Figure 6. It is observed that the $[\beta /-\beta]$ laminate is more sensitive to the fiber orientation angle than $[0 / \beta]$ lamination scheme. The adimensional frequency parameter is noticeable higher as the fiber volume fraction $k_{f}$ increases and as the boundary conditions become clamped.

Finally, the first four free vibration coefficients are presented in Table 8 to illustrate the influence of various fiber volume fractions and boundary conditions on the dynamical behavior of an unsymmetric $\left[0^{\circ} / 45^{\circ}\right]$ laminated plate.

\section{Concluding Remarks}

A Ritz approach for free vibration analysis of general laminated plates with edges elastically restrained against translation and rotation is presented in this work. The study 
TABLE 7: (a) Frequency parameters $\bar{\omega}_{i}$ for $\left[0^{\circ} / 45^{\circ}\right.$ ] carbon-epoxy AS4-3501-6 (Table 1), with different translational restraint parameter $T_{i}^{w}$, $T_{i}^{u}=T_{i}^{v}=R_{i}=0(i=1, . ., 4)$, and $a / h=10$. (b) Frequency parameters $\bar{\omega}_{i}$ for $\left[0^{\circ} / 45^{\circ}\right]$ carbon-epoxy AS4-3501-6 (Table 1), with different rotational restraint parameter $R_{i}, T_{i}^{w}=T_{i}^{u}=T_{i}^{v}=\infty(i=1, \ldots, 4)$, and $a / h=10$.

(a)

\begin{tabular}{|c|c|c|c|c|c|c|c|c|}
\hline \multirow{2}{*}{$k_{f}$} & \multirow{2}{*}{ Mode } & \multicolumn{7}{|c|}{ Translational restraint parameter $T_{i}^{w}$} \\
\hline & & 0.1 & 1 & 10 & 100 & 1000 & 10000 & $1.00 E+10$ \\
\hline \multicolumn{9}{|c|}{$a / b=2$} \\
\hline \multirow{4}{*}{0.2} & 1 & 0.158 & 0.464 & 1.043 & 2.045 & 2.778 & 2.903 & 2.917 \\
\hline & 2 & 0.184 & 0.574 & 1.625 & 3.592 & 4.520 & 4.704 & 4.726 \\
\hline & 3 & 0.255 & 0.793 & 2.167 & 3.948 & 6.915 & 7.139 & 7.149 \\
\hline & 4 & 1.652 & 1.823 & 2.838 & 5.127 & 7.177 & 7.419 & 7.449 \\
\hline \multirow{3}{*}{0.4} & 1 & 0.199 & 0.578 & 1.268 & 2.392 & 3.046 & 3.144 & 3.156 \\
\hline & 2 & 0.233 & 0.723 & 1.999 & 4.175 & 5.024 & 5.169 & 5.186 \\
\hline & 3 & 0.322 & 0.999 & 2.649 & 4.774 & 7.759 & 8.125 & 8.148 \\
\hline \multirow{5}{*}{0.6} & 4 & 1.832 & 2.071 & 3.374 & 6.021 & 7.973 & 8.173 & 8.196 \\
\hline & 1 & 0.235 & 0.681 & 1.487 & 2.757 & 3.455 & 3.557 & 3.569 \\
\hline & 2 & 0.275 & 0.853 & 2.347 & 4.837 & 5.763 & 5.915 & 5.933 \\
\hline & 3 & 0.380 & 1.179 & 3.115 & 5.589 & 8.864 & 9.309 & 9.342 \\
\hline & 4 & 2.104 & 2.394 & 3.945 & 6.992 & 9.186 & 9.408 & 9.434 \\
\hline \multicolumn{9}{|c|}{$a / b=1.5$} \\
\hline \multirow{4}{*}{0.2} & 1 & 0.111 & 0.341 & 0.904 & 1.724 & 2.239 & 2.345 & 2.364 \\
\hline & 2 & 0.141 & 0.443 & 1.335 & 3.326 & 4.739 & 5.023 & 5.067 \\
\hline & 3 & 0.171 & 0.539 & 1.627 & 3.705 & 5.946 & 6.580 & 6.673 \\
\hline & 4 & 1.423 & 1.542 & 2.285 & 4.768 & 7.832 & 8.845 & 8.980 \\
\hline \multirow{3}{*}{0.4} & 1 & 0.140 & 0.429 & 1.108 & 2.012 & 2.501 & 2.598 & 2.617 \\
\hline & 2 & 0.178 & 0.559 & 1.664 & 3.964 & 5.396 & 5.649 & 5.686 \\
\hline & 3 & 0.216 & 0.681 & 2.037 & 4.480 & 6.688 & 7.229 & 7.313 \\
\hline \multirow{5}{*}{0.6} & 4 & 1.587 & 1.731 & 2.729 & 5.680 & 8.857 & 9.749 & 9.869 \\
\hline & 1 & 0.165 & 0.506 & 1.296 & 2.316 & 2.847 & 2.954 & 2.976 \\
\hline & 2 & 0.210 & 0.660 & 1.957 & 4.587 & 6.194 & 6.469 & 6.509 \\
\hline & 3 & 0.256 & 0.804 & 2.400 & 5.243 & 7.625 & 8.198 & 8.292 \\
\hline & 4 & 1.815 & 1.989 & 3.182 & 6.582 & 10.085 & 11.034 & 11.163 \\
\hline
\end{tabular}

(b)

\begin{tabular}{|c|c|c|c|c|c|c|c|c|}
\hline \multirow{2}{*}{$k_{f}$} & \multirow{2}{*}{ Mode } & \multicolumn{7}{|c|}{ Rotational restraint parameter $R_{i}^{\phi_{x}, \phi_{y}}$} \\
\hline & & 0.1 & 1 & 10 & 100 & 1000 & 10000 & $1.00 E+10$ \\
\hline \multicolumn{9}{|c|}{$a / b=2$} \\
\hline \multirow{4}{*}{0.2} & 1 & 3.444 & 3.858 & 4.588 & 4.806 & 4.833 & 4.835 & 4.836 \\
\hline & 2 & 5.467 & 5.742 & 6.278 & 6.450 & 6.472 & 6.474 & 6.474 \\
\hline & 3 & 8.161 & 8.349 & 8.750 & 8.890 & 8.908 & 8.909 & 8.910 \\
\hline & 4 & 8.357 & 8.741 & 9.485 & 9.722 & 9.751 & 9.754 & 9.754 \\
\hline \multirow{4}{*}{0.4} & 1 & 3.854 & 4.314 & 4.989 & 5.183 & 5.183 & 5.185 & 5.186 \\
\hline & 2 & 6.061 & 6.362 & 6.855 & 7.009 & 7.009 & 7.011 & 7.011 \\
\hline & 3 & 8.971 & 9.187 & 9.552 & 9.678 & 9.678 & 9.680 & 9.680 \\
\hline & 4 & 8.987 & 9.437 & 10.142 & 10.37 & 10.347 & 10.349 & 10.349 \\
\hline \multirow[t]{4}{*}{0.6} & 1 & 4.421 & 4.946 & 5.682 & 5.866 & 5.887 & 5.889 & 5.889 \\
\hline & 2 & 6.961 & 7.309 & 7.858 & 8.006 & 8.024 & 8.026 & 8.026 \\
\hline & 3 & 10.160 & 10.584 & 10.999 & 11.124 & 11.139 & 11.140 & 11.141 \\
\hline & 4 & 10.352 & 10.720 & 11.512 & 11.709 & 11.732 & 11.734 & 11.735 \\
\hline
\end{tabular}


(b) Continued.

\begin{tabular}{|c|c|c|c|c|c|c|c|c|}
\hline \multirow{2}{*}{$k_{f}$} & \multirow{2}{*}{ Mode } & \multicolumn{7}{|c|}{ Rotational restraint parameter $R_{i}^{\phi_{x}, \phi_{y}}$} \\
\hline & & 0.1 & 1 & 10 & 100 & 1000 & 10000 & $1.00 E+10$ \\
\hline \multicolumn{9}{|c|}{$a / b=1.5$} \\
\hline \multirow{4}{*}{0.2} & 1 & 2.764 & 3.203 & 4.114 & 4.438 & 4.479 & 4.483 & 4.484 \\
\hline & 2 & 5.686 & 6.122 & 7.270 & 7.771 & 7.839 & 7.846 & 7.847 \\
\hline & 3 & 7.047 & 7.669 & 9.272 & 9.946 & 10.035 & 10.045 & 10.046 \\
\hline & 4 & 9.588 & 10.107 & 11.673 & 12.471 & 12.586 & 12.598 & 12.599 \\
\hline \multirow{4}{*}{0.4} & 1 & 3.188 & 3.703 & 4.631 & 4.925 & 4.961 & 4.965 & 4.966 \\
\hline & 2 & 6.470 & 7.016 & 8.260 & 8.739 & 8.801 & 8.807 & 8.808 \\
\hline & 3 & 7.847 & 8.632 & 10.324 & 10.927 & 11.003 & 11.011 & 11.012 \\
\hline & 4 & 10.679 & 11.329 & 13.007 & 13.742 & 13.843 & 13.853 & 13.854 \\
\hline \multirow{4}{*}{0.6} & 1 & 3.663 & 4.252 & 5.272 & 5.585 & 5.624 & 5.628 & 5.628 \\
\hline & 2 & 7.394 & 8.040 & 9.448 & 9.973 & 10.040 & 10.047 & 10.048 \\
\hline & 3 & 8.920 & 9.842 & 11.721 & 12.360 & 12.440 & 12.448 & 12.449 \\
\hline & 4 & 12.113 & 12.873 & 14.748 & 15.537 & 15.643 & 15.654 & 15.655 \\
\hline
\end{tabular}

TABLE 8: Frequency parameters $\bar{\omega}_{i}$ for $\left[0^{\circ} / 45^{\circ}\right]$ carbon-epoxy AS4-3501-6 (Table 1), with different fiber volume fraction $k_{f}$ and boundary conditions. $a / h=10$.

\begin{tabular}{|c|c|c|c|c|c|}
\hline \multirow{2}{*}{ Boundary conditions } & \multirow{2}{*}{$k_{f}$} & \multicolumn{4}{|c|}{ Mode sequence number } \\
\hline & & 1 & 2 & 3 & 4 \\
\hline \multirow{8}{*}{$S_{1} S_{1} S_{1} S_{1}$} & 0.1 & 1.198 & 2.379 & 0.193 & 2.872 \\
\hline & 0.2 & 1.435 & 2.683 & 0.166 & 3.337 \\
\hline & 0.3 & 1.628 & 2.951 & 0.154 & 3.723 \\
\hline & 0.4 & 1.804 & 3.212 & 0.148 & 4.092 \\
\hline & 0.5 & 1.973 & 3.475 & 0.145 & 4.463 \\
\hline & 0.6 & 2.143 & 3.754 & 0.145 & 4.859 \\
\hline & 0.7 & 2.319 & 4.054 & 0.146 & 5.290 \\
\hline & 0.8 & 2.489 & 4.344 & 0.148 & 5.724 \\
\hline \multirow{8}{*}{$C_{1} C_{1} C_{1} C_{1}$} & 0.1 & 1.826 & 3.091 & 3.560 & 4.502 \\
\hline & 0.2 & 2.073 & 3.407 & 4.032 & 4.961 \\
\hline & 0.3 & 2.287 & 3.702 & 4.452 & 5.387 \\
\hline & 0.4 & 2.498 & 4.003 & 4.874 & 5.824 \\
\hline & 0.5 & 2.715 & 4.321 & 5.317 & 6.290 \\
\hline & 0.6 & 2.949 & 4.671 & 5.807 & 6.809 \\
\hline & 0.7 & 3.207 & 5.062 & 6.359 & 7.396 \\
\hline & 0.8 & 3.466 & 5.449 & 6.934 & 7.982 \\
\hline \multirow{8}{*}{$S_{2} S_{2} C_{1} C_{1}$} & 0.1 & 1.446 & 2.825 & 3.037 & 3.975 \\
\hline & 0.2 & 1.651 & 3.137 & 3.469 & 4.621 \\
\hline & 0.3 & 1.830 & 3.417 & 3.847 & 5.045 \\
\hline & 0.4 & 2.002 & 3.697 & 4.213 & 5.470 \\
\hline & 0.5 & 2.173 & 3.987 & 4.587 & 5.912 \\
\hline & 0.6 & 2.351 & 4.303 & 4.989 & 6.395 \\
\hline & 0.7 & 2.541 & 4.651 & 5.430 & 6.933 \\
\hline & 0.8 & 2.724 & 4.989 & 5.876 & 7.464 \\
\hline
\end{tabular}

includes the effective elastic moduli of each lamina obtained using the Mori-Tanaka mean field theory, which allows taking into account the influence of the fiber volume ratios and the elastic properties of the components (fiber and matrix) into the vibration behavior. The formulation is based on the first-order shear deformation theory, and the generalized displacements are approximate using sets of characteristic orthogonal polynomials generated by the Gram-Schmidt procedure. The consideration of all possible rotational and translational restraints allows generating any classical 
boundary condition, only approaching the corresponding spring parameter to zero or infinity. The algorithm is computationally efficient, and the solutions are stables and convergent. Close agreement with existing results in the literature is shown and new results are presented in tables and figures which could be useful for design and optimization problems of general long fiber-reinforced laminated plates.

\section{Appendix}

The matrices $K$ and $M$ in (18) are given by

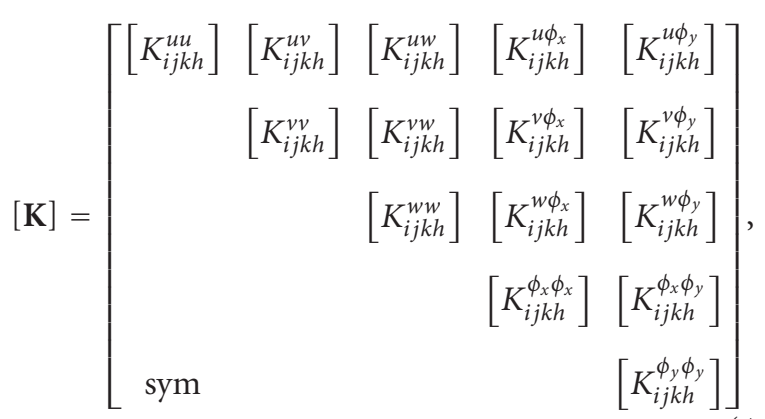

where

$$
\begin{aligned}
& 3 K_{i j k h}^{u u}=A_{11} \iint_{R} p_{i}^{(u)} p_{k}^{\prime(u)} q_{j}^{(u)} q_{h}^{(u)} d x d y \\
& +A_{16} \iint_{R}\left(p_{i}^{\prime(u)} p_{k}^{(u)} q_{j}^{(u)} q_{h}^{\prime(u)}\right. \\
& \left.+p_{i}^{(u)} p_{k}^{(u)} q_{j}^{(u)} q_{h}^{(u)}\right) d x d y \\
& +A_{66} \iint_{R} p_{i}^{(u)} p_{k}^{(u)} q_{j}^{\prime(u)} q_{h}^{\prime(u)} d x d y \\
& +t_{2}^{u} \int_{0}^{b}\left[p_{i}^{(u)} p_{k}^{(u)}\right]_{x=1} q_{j}^{(u)} q_{h}^{(u)} d y \\
& +t_{4}^{u} \int_{0}^{b}\left[p_{i}^{(u)} p_{k}^{(u)}\right]_{x=0} q_{j}^{(u)} q_{h}^{(u)} d y \\
& K_{i j k h}^{u v}=A_{12} \iint_{R} p_{i}^{(u)} p_{k}^{(v)} q_{j}^{(u)} q_{h}^{\prime(v)} d x d y \\
& +A_{16} \iint_{R} p_{i}^{(v)} p_{k}^{(u)} q_{j}^{(v)} q_{h}^{(u)} d x d y \\
& +A_{26} \iint_{R} p_{i}^{(v)} p_{k}^{(u)} q_{j}^{\prime(v)} q_{h}^{\prime(u)} d x d y \\
& +A_{66} \iint_{R} p_{i}^{\prime(v)} p_{k}^{(u)} q_{j}^{(v)} p_{h}^{\prime(u)} d x d y, \\
& K_{i j k h}^{u w}=0, \quad K_{i j k h}^{v w}=0,
\end{aligned}
$$

$$
\begin{aligned}
& K_{i j k h}^{u \phi_{x}}=B_{11} \iint_{R} p_{i}^{\prime(u)} p_{k}^{\prime\left(\phi_{x}\right)} q_{j}^{(u)} q_{h}^{\left(\phi_{x}\right)} d x d y \\
& +B_{16} \iint_{R} p_{i}^{(u)} p_{k}^{\left(\phi_{x}\right)} q_{j}^{(u)} q_{h}^{\left(\phi_{x}\right)} d x d y \\
& +B_{16} \iint_{R} p_{i}^{(u)} p_{k}^{\left(\phi_{x}\right)} q_{j}^{\prime(u)} q_{h}^{\left(\phi_{x}\right)} d x d y \\
& +B_{66} \iint_{R} p_{i}^{(u)} p_{k}^{\left(\phi_{x}\right)} q_{j}^{\prime(u)} p_{h}^{\prime\left(\phi_{x}\right)} d x d y, \\
& K_{i j k h}^{u \phi_{y}}=B_{12} \iint_{R} p_{i}^{(u)} p_{k}^{\left(\phi_{y}\right)} q_{j}^{(u)} q_{h}^{\prime\left(\phi_{y}\right)} d x d y \\
& +B_{16} \iint_{R} p_{i}^{(u)} p_{k}^{\left(\phi_{y}\right)} q_{j}^{(u)} q_{h}^{\left(\phi_{y}\right)} d x d y \\
& +B_{26} \iint_{R} p_{i}^{(u)} p_{k}^{\left(\phi_{y}\right)} q_{j}^{\prime(u)} q_{h}^{\prime\left(\phi_{y}\right)} d x d y \\
& +B_{66} \iint_{R} p_{i}^{(u)} p_{k}^{\left(\phi_{y}\right)} q_{j}^{\prime(u)} q_{h}^{\left(\phi_{y}\right)} d x d y, \\
& K_{i j k h}^{v v}=A_{22} \iint_{R} p_{i}^{(v)} p_{k}^{(v)} q_{j}^{(v)} q_{h}^{(v)} d x d y \\
& +A_{26} \iint_{R}\left(p_{i}^{(v)} p_{k}^{(v)} q_{j}^{(v)} q_{h}^{(v)}\right.
\end{aligned}
$$

$$
\begin{aligned}
& \left.+p_{i}^{(v)} p_{k}^{(v)} q_{j}^{(v)} q_{h}^{(v)}\right) d x d y \\
& +A_{66} \iint_{R} p_{i}^{(v)} p_{k}^{(v)} q_{j}^{(v)} q_{h}^{(v)} d x d y \\
& +t_{1}^{v} \int_{0}^{a} p_{i}^{(v)} p_{k}^{(v)}\left[q_{j}^{(v)} q_{h}^{(v)}\right]_{y=0} d x \\
& +t_{3}^{v} \int_{0}^{b} p_{i}^{(v)} p_{k}^{(v)}\left[q_{j}^{(v)} q_{h}^{(v)}\right]_{y=1} d x, \\
& K_{i j k h}^{v \phi_{x}}=B_{12} \iint_{R} p_{i}^{(v)} p_{k}^{\left(\phi_{x}\right)} q_{j}^{(v)} q_{h}^{\left(\phi_{x}\right)} d x d y \\
& +B_{16} \iint_{R} p_{i}^{(v)} p_{k}^{\left(\phi_{x}\right)} q_{j}^{(v)} q_{h}^{\left(\phi_{x}\right)} d x d y \\
& +B_{26} \iint_{R} p_{i}^{(v)} p_{k}^{\left(\phi_{x}\right)} q_{j}^{\prime(v)} q_{h}^{\left(\phi_{x}\right)} d x d y \\
& +B_{66} \iint_{R} p_{i}^{(v)} p_{k}^{\left(\phi_{x}\right)} q_{j}^{(v)} q_{h}^{\left(\phi_{x}\right)} d x d y, \\
& K_{i j k h}^{v \phi_{y}}=B_{22} \iint_{R} p_{i}^{(v)} p_{k}^{\left(\phi_{y}\right)} q_{j}^{(v)} q_{h}^{\prime\left(\phi_{y}\right)} d x d y \\
& +B_{26} \iint_{R} p_{i}^{(v)} p_{k}^{\prime\left(\phi_{y}\right)} q_{j}^{\prime(v)} q_{h}^{\left(\phi_{y}\right)} d x d y \\
& +B_{26} \iint_{R} p_{i}^{(v)} p_{k}^{\left(\phi_{y}\right)} q_{j}^{(v)} q_{h}^{\left(\phi_{y}\right)} d x d y \\
& +B_{66} \iint_{R} p_{i}^{(v)} p_{k}^{\prime\left(\phi_{y}\right)} q_{j}^{(v)} q_{h}^{\left(\phi_{y}\right)} d x d y,
\end{aligned}
$$




$$
\begin{aligned}
& K_{i j k h}^{w w}=A_{44} \iint_{R} p_{i}^{(w)} p_{k}^{(w)} q_{j}^{(w)} q_{h}^{(w)} d x d y \\
& +A_{55} \iint_{R} p_{i}^{(w)} p_{k}^{(w)} q_{j}^{(w)} q_{h}^{(w)} d x d y \\
& +A_{45} \iint_{R}\left(p_{i}^{(w)} p_{k}^{(w)} q_{j}^{(w)} q_{h}^{\prime(w)}\right. \\
& \left.+p_{i}^{(w)} p_{k}^{\prime(w)} q_{j}^{\prime(w)} q_{h}^{(w)}\right) d x d y \\
& +t_{1}^{w} \int_{0}^{a} p_{i}^{(w)} p_{k}^{(w)}\left[q_{j}^{(w)} q_{h}^{(w)}\right]_{y=0} d x \\
& +t_{2}^{w} \int_{0}^{b}\left[p_{i}^{(w)} p_{k}^{(w)}\right]_{x=1} q_{j}^{(w)} q_{h}^{(w)} d y \\
& +t_{3}^{w} \int_{0}^{a} p_{i}^{(w)} p_{k}^{(w)}\left[q_{j}^{(w)} q_{h}^{(w)}\right]_{y=1} d x \\
& +t_{4}^{w} \int_{0}^{b}\left[p_{i}^{(w)} p_{k}^{(w)}\right]_{x=0} q_{j}^{(w)} q_{h}^{(w)} d y, \\
& K_{i j k h}^{w \phi_{x}}=K\left(A_{45} \iint_{R} p_{i}^{(w)} p_{k}^{\left(\phi_{x}\right)} q_{j}^{(w)} q_{h}^{\left(\phi_{x}\right)} d x d y\right. \\
& \left.+A_{55} \iint_{R} p_{i}^{(w)} p_{k}^{\left(\phi_{x}\right)} q_{j}^{(w)} q_{h}^{\left(\phi_{x}\right)} d x d y\right), \\
& K_{i j k h}^{w \phi_{y}}=K\left(A_{44} \iint_{R} p_{i}^{(w)} p_{k}^{\left(\phi_{y}\right)} q_{j}^{(w)} q_{h}^{\left(\phi_{y}\right)} d x d y\right. \\
& \left.+A_{45} \iint_{R} p_{i}^{(w)} p_{k}^{\left(\phi_{y}\right)} q_{j}^{(w)} q_{h}^{\left(\phi_{y}\right)} d x d y\right), \\
& K_{i j k h}^{\phi_{x} \phi_{x}}=K A_{55} \iint_{R} p_{i}^{\left(\phi_{x}\right)} p_{k}^{\left(\phi_{x}\right)} q_{j}^{\left(\phi_{x}\right)} q_{h}^{\left(\phi_{x}\right)} d x d y \\
& +D_{11} \iint_{R} p_{i}^{\left(\phi_{x}\right)} p_{k}^{\left(\phi_{x}\right)} q_{j}^{\left(\phi_{x}\right)} q_{h}^{\left(\phi_{x}\right)} d x d y \\
& +D_{16} \iint_{R}\left(p_{i}^{\prime\left(\phi_{x}\right)} p_{k}^{\left(\phi_{x}\right)} q_{j}^{\left(\phi_{x}\right)} q_{h}^{\prime\left(\phi_{x}\right)}\right. \\
& \left.+p_{i}^{\left(\phi_{x}\right)} p_{k}^{\left(\phi_{x}\right)} q_{j}^{\prime\left(\phi_{x}\right)} q_{h}^{\left(\phi_{x}\right)}\right) d x d y \\
& +D_{66} \iint_{R} p_{i}^{\left(\phi_{x}\right)} p_{k}^{\left(\phi_{x}\right)} q_{j}^{\prime\left(\phi_{x}\right)} q_{h}^{\left(\phi_{x}\right)} d x d y \\
& +r_{2} \int_{0}^{b}\left[p_{i}^{\left(\phi_{x}\right)} p_{k}^{\left(\phi_{x}\right)}\right]_{x=a} q_{j}^{\left(\phi_{x}\right)} q_{h}^{\left(\phi_{x}\right)} d y \\
& +r_{4} \int_{0}^{b}\left[p_{i}^{\left(\phi_{x}\right)} p_{k}^{\left(\phi_{x}\right)}\right]_{x=0} q_{j}^{\left(\phi_{x}\right)} q_{h}^{\left(\phi_{x}\right)} d y, \\
& K_{i j k h}^{\phi_{x} \phi_{y}}=K A_{45} \iint_{R} p_{i}^{\left(\phi_{x}\right)} p_{k}^{\left(\phi_{y}\right)} q_{j}^{\left(\phi_{x}\right)} q_{h}^{\left(\phi_{y}\right)} d x d y \\
& +D_{12} \iint_{R} p_{i}^{\prime\left(\phi_{x}\right)} p_{k}^{\left(\phi_{y}\right)} q_{j}^{\left(\phi_{x}\right)} q_{h}^{\prime\left(\phi_{y}\right)} d x d y \\
& +D_{16} \iint_{R} p_{i}^{\left(\phi_{x}\right)} p_{k}^{\left(\phi_{y}\right)} q_{j}^{\left(\phi_{x}\right)} q_{h}^{\left(\phi_{y}\right)} d x d y \\
& +D_{26} \iint_{R} p_{i}^{\left(\phi_{x}\right)} p_{k}^{\left(\phi_{y}\right)} q_{j}^{\prime\left(\phi_{x}\right)} q_{h}^{\left(\phi_{y}\right)} d x d y \\
& +D_{66} \iint_{R} p_{i}^{\left(\phi_{x}\right)} p_{k}^{\prime\left(\phi_{y}\right)} q_{j}^{\prime\left(\phi_{x}\right)} q_{h}^{\left(\phi_{y}\right)} d x d y,
\end{aligned}
$$

with $K=5 / 6$

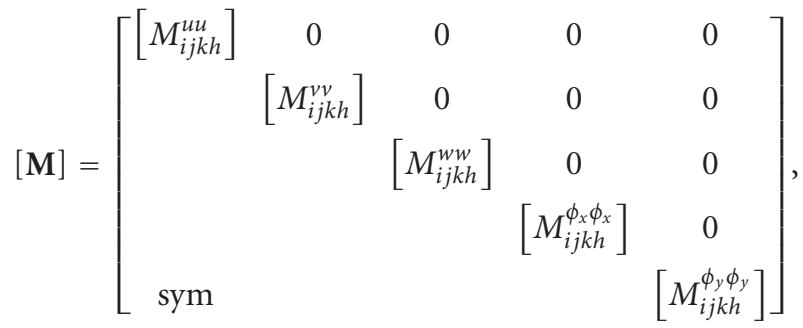

$$
\begin{aligned}
& M_{i j k h}^{u u}=I_{0} \iint_{R} p_{i}^{(u)} p_{k}^{(u)} q_{j}^{(u)} q_{h}^{(u)} d x d y, \\
& M_{i j k h}^{v v}=I_{0} \iint_{R} p_{i}^{(v)} p_{k}^{(v)} q_{j}^{(v)} q_{h}^{(v)} d x d y, \\
& M_{i j k h}^{w w}=I_{0} \iint_{R} p_{i}^{(w)} p_{k}^{(w)} q_{j}^{(w)} q_{h}^{(w)} d x d y, \\
& M_{i j k h}^{\phi_{x} \phi_{x}}=I_{2} \iint_{R} p_{i}^{\left(\phi_{x}\right)} p_{k}^{\left(\phi_{x}\right)} q_{j}^{\left(\phi_{x}\right)} q_{h}^{\left(\phi_{x}\right)} d x d y, \\
& M_{i j k h}^{\phi_{y} \phi_{y}}=I_{2} \iint_{R} p_{i}^{\left(\phi_{y}\right)} p_{k}^{\left(\phi_{y}\right)} q_{j}^{\left(\phi_{y}\right)} q_{h}^{\left(\phi_{y}\right)} d x d y .
\end{aligned}
$$

\section{Acknowledgment}

The authors wish to thank the economic support of CONICET (PIP no. 0105/2010) and CIUNSa.

\section{References}

[1] E. Reissner, "On transverse bending of plates, including the effect of transverse shear deformation," International Journal of Solids and Structures, vol. 11, no. 5, pp. 569-576, 1975.

[2] R. D. Mindlin, "Influences of rotatory inertia and shear inflexural motion of isotropic, elastic plates," Journal of Applied Mechanics, vol. 18, pp. 1031-1036, 1951.

[3] H. R. H. Kabir, "On the frequency response of moderately thick simply supported rectangular plates with arbitrary lamination," International Journal of Solids and Structures, vol. 36, no. 15 , pp. 2285-2301, 1999. 
[4] K. M. Liew, "Solving the vibation of thick symmetric laminates by Reissner/Mindlin plate theory and the p-Ritz method," Journal of Sound and Vibration, vol. 198, no. 3, pp. 343-360, 1996.

[5] J. W. Shi, A. Nakatani, and H. Kitagawa, "Vibration analysis of fully clamped arbitrarily laminated plate," Composite Structures, vol. 63, no. 1, pp. 115-122, 2004.

[6] M. Aydogdu and T. Timarci, "Vibration analysis of cross-ply laminated square plates with general boundary conditions," Composites Science and Technology, vol. 63, no. 7, pp. 10611070, 2003.

[7] L. Liu, L. P. Chua, and D. N. Ghista, "Mesh-free radial basis function method for static, free vibration and buckling analysis of shear deformable composite laminates," Composite Structures, vol. 78, no. 1, pp. 58-69, 2007.

[8] G. R. Liu, X. Zhao, K. Y. Dai, Z. H. Zhong, G. Y. Li, and X. Han, "Static and free vibration analysis of laminated composite plates using the conforming radial point interpolation method," Composites Science and Technology, vol. 68, no. 2, pp. 354-366, 2008.

[9] J. Wang, K. M. Liew, M. J. Tan, and S. Rajendran, "Analysis of rectangular laminated composite plates via FSDT meshless method," International Journal of Mechanical Sciences, vol. 44, no. 7, pp. 1275-1293, 2002.

[10] K. S. Numayr, R. H. Haddad, and M. A. Haddad, "Free vibration of composite plates using the finite difference method," Thin-Walled Structures, vol. 42, no. 3, pp. 399-414, 2004.

[11] W. Lanhe, L. Hua, and W. Daobin, "Vibration analysis of generally laminated composite plates by the moving least squares differential quadrature method," Composite Structures, vol. 68, no. 3, pp. 319-330, 2005.

[12] P. Ribeiro, "First-order shear deformation, p-version, finite element for laminated plate nonlinear vibrations," AIAA Journal, vol. 43, no. 6, pp. 1371-1379, 2005.

[13] A. J. M. Ferreira and G. E. Fasshauer, "Analysis of natural frequencies of composite plates by an RBF-pseudospectral method," Composite Structures, vol. 79, no. 2, pp. 202-210, 2007.

[14] P. Malekzadeh and S. A. Shahpari, "Free vibration analysis of variable thickness thin and moderately thick plates with elastically restrained edges by DQM," Thin-Walled Structures, vol. 43, no. 7, pp. 1037-1050, 2005.

[15] F. Ohya, M. Ueda, T. Uchiyama, and M. Kikuchi, "Free vibration analysis by the superposition method of rectangular Mindlin plates with internal columns resting on uniform elastic edge supports," Journal of Sound and Vibration, vol. 289, no. 1-2, pp. 1-24, 2006.

[16] D. Zhou, "Vibrations of Mindlin rectangular plates with elastically restrained edges using static Timoshenko beam functions with the Rayleigh-Ritz method," International Journal of Solids and Structures, vol. 38, no. 32-33, pp. 5565-5580, 2001.

[17] K. Khorshidi, "Vibro-acoustic analysis of Mindlin rectangular plates resting on an elastic foundation," Scientia Iranica, vol. 18, no. 1, pp. 60-69, 2001.

[18] L. H. Wu and Y. Lu, "Free vibration analysis of rectangular plates with internal columns and uniform elastic edge supports by pb-2 Ritz method," International Journal of Mechanical Sciences, vol. 53, no. 7, pp. 494-504, 2011.

[19] G. Y. Jin, H. Chen, J. T. Du, T. J. Yang, and W. Y. Li, “The Influence of edge restraining stiffness on the transverse vibrations of rectangular plate structures," Journal of Marine Science and Application, vol. 9, no. 4, pp. 393-402, 2010.
[20] A. R. Setoodeh and G. Karami, "A solution for the vibration and buckling of composite laminates with elastically restrained edges," Composite Structures, vol. 60, no. 3, pp. 245253, 2003.

[21] G. Karami, P. Malekzadeh, and S. R. Mohebpour, "DQM free vibration analysis of moderately thick symmetric laminated plates with elastically restrained edges," Composite Structures, vol. 74, no. 1, pp. 115-125, 2006.

[22] A. S. Ashour, "Vibration of angle-ply symmetric laminated composite plates with edges elastically restrained," Composite Structures, vol. 74, no. 3, pp. 294-302, 2006.

[23] L. G. Nallim and R. O. Grossi, "Vibration of angle-ply symmetric laminated composite plates with edges elastically restrained," Composite Structures, vol. 81, no. 1, pp. 80-83, 2007.

[24] S. Chakraverty and M. Petyt, "Natural frequencies for free vibration of nonhomogeneous elliptic and circular plates using two-dimensional orthogonal polynomials," Applied Mathematical Modelling, vol. 21, no. 7, pp. 399-417, 1997.

[25] B. Singh and S. Chakraverty, "Flexural vibration of skew plates using boundary characteristic orthogonal polynomials in two variables," Journal of Sound and Vibration, vol. 173, no. 2, pp. 157-178, 1994.

[26] S. Chakraverty, R. B. Bhat, and I. Stiharu, "Free vibration of annular elliptic plates using boundary characteristic orthogonal polynomials as shape functions in the Rayleigh-Ritz method," Journal of Sound and Vibration, vol. 241, no. 3, pp. 524-539, 2001.

[27] S. T. Chow, K. M. Liew, and K. Y. Lam, "Transverse vibration of symmetrically laminated rectangular composite plates," Composite Structures, vol. 20, no. 4, pp. 213-226, 1992.

[28] H. Altenbach, J. Altenbach, and W. Kisssing, Mechanics of Composite Structural Elements, Springer, Berlin, Germany, 2004.

[29] T. Mori and K. Tanaka, "Average stress in matrix and average elastic energy of materials with misfitting inclusions," Acta Metallurgica, vol. 21, no. 5, pp. 571-574, 1973.

[30] P. D. Soden, M. J. Hinton, and A. S. Kaddour, "Lamina properties, lay-up configurations and loading conditions for a range of fibre-reinforced composite laminates," Composites Science and Technology, vol. 58, no. 7, pp. 1011-1022, 1998.

[31] A. Alibeigloo, M. Shakeri, and M. R. Kari, "Free vibration analysis of antisymmetric laminated rectangular plates with distributed patch mass using third-order shear deformation theory," Ocean Engineering, vol. 35, no. 2, pp. 183-190, 2008.

[32] J. N. Reddy, "A simple higher-order theory for laminated composite plates," ASME Journal of Applied Mechanics, vol. 51, no. 4, pp. 745-752, 1984.

[33] J. D. Eshelby, "The determination of the elastic field of an ellipsoidal inclusion and related problems," Proceedings of the Royal Society, vol. 241, pp. 376-396, 1957.

[34] G. P. Tandon and G. J. Weng, "The effect of aspect ratio of inclusions on the elastic properties of unidirectionally aligned composites," Polymer Composites, vol. 5, no. 4, pp. 327-333, 1984.

[35] J. N. Reddy, Mechanics of Laminated Composite Plates and Shells: Theory and Analysis, CRC Press, Boca Raton, Fla, USA, 2nd edition, 2003.

[36] J. M. Whitney, Structural Analysis of Laminated Anisotropic Plates, Technomic Publishing Co., Lancaster, Pa, USA, 1987.

[37] L. G. Nallim and R. O. Grossi, "On the use of orthogonal polynomials in the study of anisotropic plates," Journal of Sound and Vibration, vol. 264, no. 5, pp. 1201-1207, 2003.

[38] L. G. Nallim and S. Oller, "An analytical-numerical approach to simulate the dynamic behaviour of arbitrarily laminated 
composite plates," Composite Structures, vol. 85, no. 4, pp. 311325,2008

[39] R. B. Bhat, "Plate deflection using orthogonal polynomials," Journal of Engineering Mechanics, vol. 101, no. 11, pp. 13011309, 1985.

[40] N. M. Auciello and A. Ercolano, "A general solution for dynamic response of axially loaded non-uniform Timoshenko beams," International Journal of Solids and Structures, vol. 41, no. 18-19, pp. 4861-4874, 2004. 

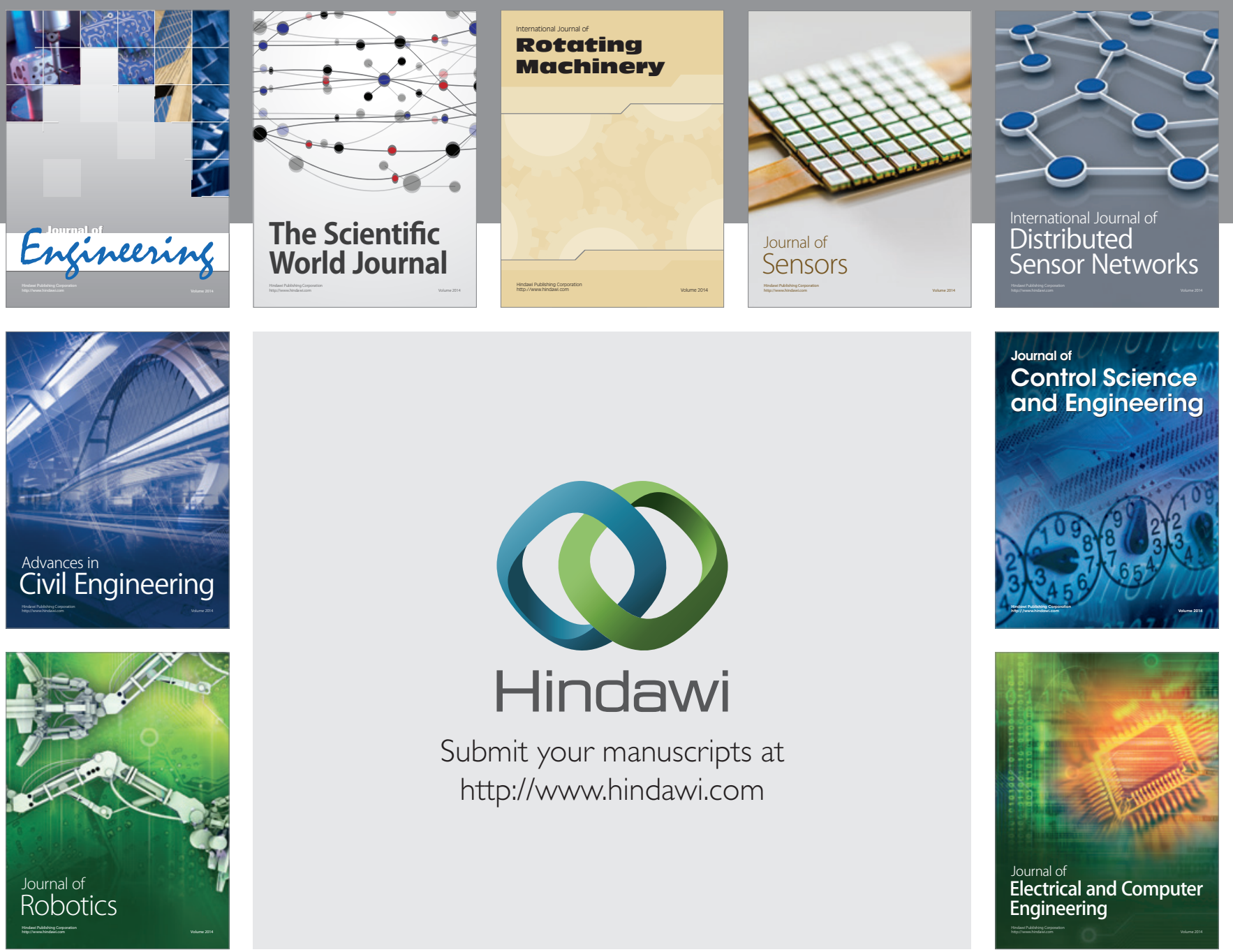

Submit your manuscripts at

http://www.hindawi.com
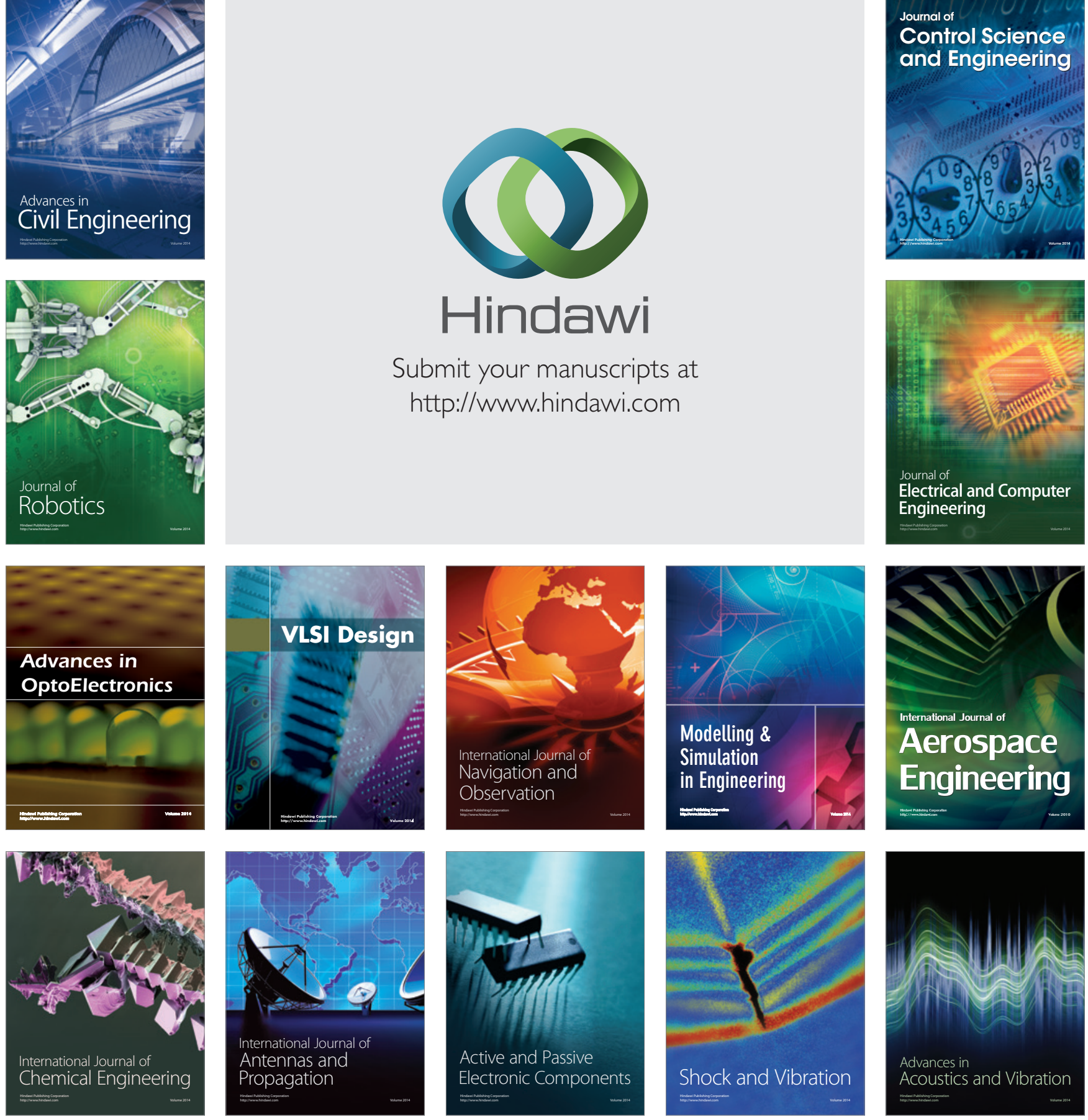